\title{
The beneficial role of Probiotics in monogastric animal nutrition and health
}

\begin{abstract}
The practice of probiotics in farm animals' health and production has increased significantly over the last 15 years. Probiotics are defined as live microorganisms that can confer a health benefit for the host when administered in appropriate and regular quantities. The isolation and identification of microorganisms is the first step in the selection of potential probiotics from gut, feces and milk of respective animals. The present molecular techniques mainly genomic and proteomic-knowledge based are employed to identify, characterize probiotics. The ability to examine fully sequenced genomes has accelerated the application of genetic approaches to elucidate the functional roles in the selection of new and specific probiotics. Identification of suitable probiotics may prove to be the next step to decrease the risk of intestinal diseases and reduce specific microbial disorders, as well as demonstrating their role in the production performance of animals, safety and wholesomeness of animals' meat evidencing consumer's protection. The mechanisms of action of probiotics include the inhibition of pathogen growth by competition for nutritional sources and adhesion sites, secretion of antimicrobial substances and toxin inactivation. Consequently, the primary interest in the application of probiotics has been in the prevention and treatment of gastrointestinal infections and antibiotic-associated animals' diarrheal diseases. In this review, the most important benefits of probiotics upon the gastrointestinal microbial ecosystem in monogastric animals (equines, pigs, veal calf and poultry) are described, as well as their implications in terms of animal nutrition and health. Additional knowledge on the possible mechanisms of action is also provided.
\end{abstract}

Keywords: probiotics, competitive exclusion, pig, poultry, veal calf, horse
Volume 2 Issue 4 - 2015

\author{
Ahasan ASML, Agazzi A, Invernizzi G, \\ Bontempo V, Savoini G \\ Dipartimento di Scienze veterinarie per la salute, Università \\ degli Studi di Milano, Italy
}

\begin{abstract}
Correspondence: Alessandro Agazzi, Dipartimento di Scienze veterinarie per la salute, la produzione animale e la sicurezza alimentare, Università degli Studi di Milano, Milano, Italy, via Celoria 10, 20133 Milan, Italy, Tel +39025 03। 8038, Fax +39 025031 7819, Email alessandro.agazzi@unimi.it
\end{abstract}

Received: May 18, 2015 | Published: June 27, 2015

\section{Introduction}

Dense and complex microbial communities reside in the gastrointestinal tract of domestic animals, which can be composed of bacteria, protozoa, fungi, archaea, and viruses. Extensive research has been dedicated during the last 30years to characterization of digestive microbial composition and functional diversity, which has directed to a better understanding of the major involvement of the gut microbiota to animal nutrition and health. Amongst the valuable effects, gastrointestinal tract microbial communities are aimed to digestion and fermentation of plant polymers, which is of specific significance in herbivorous animals. Moreover, the indigenous gut microbiota is accountable for the synthesis of vitamins, bioconversion of toxic compounds to non-toxic residues, stimulation of the immune system, maintenance of gut peristalsis and intestinal mucosal integrity and plays a barrier role against colonization by pathogens. ${ }^{1}$

In this context, the possibility to use feed supplements to achieve better animal health, welfare and productivity through manipulation of the gut micro biota ecosystem has gained considerable attention in the last three decades. The main effects of these additives, pro biotics on top of others, are a facilitated resistance to pathogenic bacteria colonization and enhanced host mucosa immunity, thus causing a reduced pathogen load, an improved health status of the animals ${ }^{2,3}$ and a reduced risk of food-borne pathogens in foods.

\section{What is a probiotics?}

Over the years, probiotic in the world has been used in a number of different ways. The use of probiotics in farm animals dates back 75 years, but in the 1960s, for the first time it was demonstrated that
Lactobacillus was able to significantly stimulate growth on pigs. ${ }^{4}$ Chow ${ }^{5}$ reported the concept that food could be provided as medicine. ${ }^{5}$ This concept was first conceived thousands of years ago by Hippocrates (Greek philosopher and father of medicine), who once wrote: 'Let food be thy medicine, and medicine be thy food'. Nonetheless, during current times, the notion of food having medicinal value has been reborn as 'functional foods'. ${ }^{5}$ In the general term "functional foods", probiotics have quickly gained attention in the field of self-care and complementary medicine. ${ }^{6}$ Modern consumers in the world are progressively paying more attention to their personal health in order to preventing and/or curing illness through daily foods. Microbes have been used in food and alcoholic fermentations since many years, but most recently have undergone scientific scrutiny to examine their possible health benefits. The word "probiotic" comes from the Greek words "pro" and "biotic," meaning "for the life", 7 and has been defined as "a live microbial feed supplement which beneficially affects the host animal by improving its intestinal microbial balance". ${ }^{8}$ Probiotics are microbial cell preparations or components of microbial cells that have a beneficial effect on the health and well-being of the host. ${ }^{9}$ Probiotics are not necessary to be viable, as nonviable forms have also been proved to provide health effects. ${ }^{10}$ It is thought to reduce potentially harmful bacteria from the intestine and to improve microbial balances in intestine and exert positive health effects on the host..$^{8-11}$ Today, the term "probiotic" refers to "live microorganisms which, administered in adequate amounts, confer a beneficial physiological effect on the host," according to the Food and Agriculture Organization and World Health Organization. ${ }^{12}$

The protective flora naturally present in the gut is very stable; however, it can be influenced by some dietary and environmental 
factors such as hygiene conditions, antibiotic therapy and stress factors. ${ }^{8}$ In the wild state, young animal picks up its gut flora mainly from its mother by direct or indirect routes. However, modern methods of animal rearing often restrict the access that the infant has to the mother and prevents it acquiring the full complement of characteristic microbes. But, probiotic and competitive exclusion microorganisms would protect the newborn young animal against infection (Figure 1). Competitive exclusion cultures are composed of a mixture of non-pathogenic bacteria (probiotic culture) typically found in the gastrointestinal tract of the animal which are administered only in a single dose to the neonatal animal, such as the day-old chick or a newborn piglet, demonstrating the impact of the gut microbiota on gut function and disease resistance ${ }^{13,14}$ and also that they can help to reestablish the gastrointestinal tract flora after antimicrobial treatment. ${ }^{15}$ Because of the susceptibility of newborn animals to infection, this practice is also of commercial importance. By using this model, a number of probiotics ${ }^{13,16-19}$ have been shown to prevent colonization and shedding of Salmonella and Campylobacter at farm level to control food borne diseases.

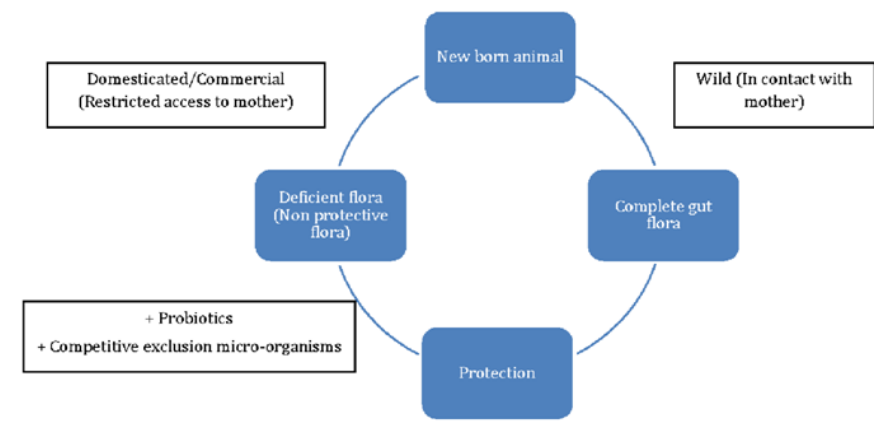

Figure I Schematic representation of the concept of probiotic, modified from. ${ }^{8,20-23}$

The microbial species recently being used in probiotics mixtures are many and varied. The major microbial groups such as Bacteroides, Clostridium, Bifidobacterium, Eubacterium, Lactobacillus, Enterobacteriaceae, Streptococcus, Fusobacterium, Peptostreptococcus and Propionibacterium are used in monogastric animals (such as pig, chicken, rabbit and man). On the other hand, in polygastric animals, (such as cow, sheep and lamb), the rumen is the most vital microbial ecosystem with the majority of fiber-degrading groups belonging to Fibrobacter, Ruminococcus, Butyrivibrio and Bacteroides together with major groups such as Prevotella, Selenomonas, Streptococcus, Lactobacillus and Megasphaera. Moreover, the rumen maintains some anaerobic fungi, ciliate protozoa and a large number of methanogens to keep normal rumen microenvironment. ${ }^{24} \mathrm{~A}$ list of the probiotic species used in studies or in livestock feeding and health is shown in Table 1. Mammals age, diet, health and pathological status might be influenced by the percentage of individual/various microbial groups..$^{25,26}$ Normally, herbivores, carnivores and omnivores are respectively characterized by a high, low and intermediate number of bacterial phyla. ${ }^{27}$

To ensure successful application, probiotics must have important characteristics such as resistance to gastrointestinal conditions (gastric acid and bile), ability to adhere to the gastrointestinal mucosa and competitive exclusion of pathogens. ${ }^{52}$ The expected health-promoting characteristics and safely criteria of probiotics are shown in Table 2.

\section{Historical use of probiotics}

The Bible and the sacred books of Hinduism mentioning about the origin of cultured dairy products dates back to the dawn of civilization. Climatic conditions sure effect for the development of many of the traditional soured milk or cultured dairy products such as kefir, koumiss, leben and dahi. ${ }^{56}$ Many of these products are still extensively consumed, had frequently been used therapeutically before the existence of bacteria was recognized..$^{57}$ The basic concept of "probiotics" appeared long time ago when they were consumed, either as natural components of food, or as fermented foods. The interest in intestinal microbiology and dietary use of probiotics began in the late 1800 s and early 1900s. The growing interest was also motivated by Escherich's isolation of Escherichia coli in the late $1800 \mathrm{~s}$, as well as active research on the benefits of feeding lactic acid bacteria and lactose near the turn of the 20th century. ${ }^{58}$ The Nobel laureate Elie Metchnikoff noticed the high life expectancy of Bulgarians who consumed yogurt. In 1907, he reported that the indigenous bacteria were harmful and that ingestion of lactic acid bacteria in yogurt had a positive influence on health. ${ }^{59,60} \mathrm{He}$ named the microorganism significant for the fermentation Bacillus bulgaricus, later classified as Lactobacillus bulgaricus that was used for the prevention of human scours and gastrointestinal diseases as early as the 1920s. At the same period, a French pediatrician, Henry Tissier, studied that infants suffering with diarrhea had a small number of $Y$ shaped gram-positive bacteria in their stools, while healthy infant's stools contain a dominant number of these "bifid" bacteria. He even recommended, in a report to the Biology Society, to make children presenting with diarrhea drinking " 1 to 2 Bordeaux glasses of a pure culture of Bacillus acidi paralactici, or even better of a symbiosis of this species with Bacillus bifidus, to accelerate the building up of a preventing flora".

The word probiotic was first mentioned by Lilly \& Stillwell in 1965 , as opposite to the word antibiotic, to qualify "a microbial substance able to stimulate the growth of another microorganism". Subsequently, the concept of microbial origin was introduced, redefining probiotics as "living micro-organisms with beneficial effects on the host, by modifying the equilibrium of its gut microbiota". During the following decades until the 1960s and 1970s, there was little implication in probiotics when they were rediscovered for mammalian nutrition mainly human and animal. The primary potent probiotic products for animal nutrition that accomplished to the exact requirements for feed additives did not emerge on the European market until the mid-1980s. ${ }^{53}$ Over a century, Eastern Europeans and Asians used probiotics invariably containing lactic acid bacteria and Bifidobacteria as a natural remedy to prevent and treat infections of the urogenital, intestinal tracts and skin in humans and animals as yogurt and drinks. The results of numerous in vitro and in vivo studies, in animal models and clinical trials have proven the potential of these probiotics to prevent many diseases and disturbances of the intestinal microbiota that could increase susceptibility to infection. ${ }^{59,60}$

\section{Global probiotics market}

Interest and demand for probiotics are increased all over the world, driven by promising new products in the market and by consumers looking for safe therapeutic and preventive health benefits. The major factors driving the growth of the global probiotic market include growing health consciousness of the population and the availability of probiotics in the form of dietary supplements. In 1999, the Agrifood trade in Europe boasted a $48 \%$ increase in turnover with probiotic products. ${ }^{61}$ Indeed, the global use of probiotic ingredients, supplements and food is seen as a rapidly expanding market. Global sales of probiotic ingredients, supplements and foods amounted to 
USD 21.6billion in 2010 and USD 24.23billion in 2011. Based on a new market statement available by Transparency Market Research, "Probiotics Market (Dietary Supplements, Animal Feed, Foods \& Beverages): Global Industry Analysis, Market Size, Share, Trends, Analysis, Growth and Forecast", the global market of probiotic is anticipated to achieve USD 31.1 billion by 2015 as well as a compound annual growth rate (CAGR) of $7.6 \%$ over the previous 5 year period.
It will be predictable to reach USD 44.9billion in 2018. Asia-Pacific and Europe lead the global probiotics market owning to its demand, whereas Asia-Pacific is also expected to be the most promising market in the near future. ${ }^{62}$ Asia-Pacific is the probiotics market leader, with an anticipated to reach CAGR of 7.0\% from 2013 to 2018. In AsiaPacific, China and Japan lead the market income for probiotics. Also India and other regions are showing significant growth.

Table I Some microbial species of potential use as livestock probiotics with their benefits

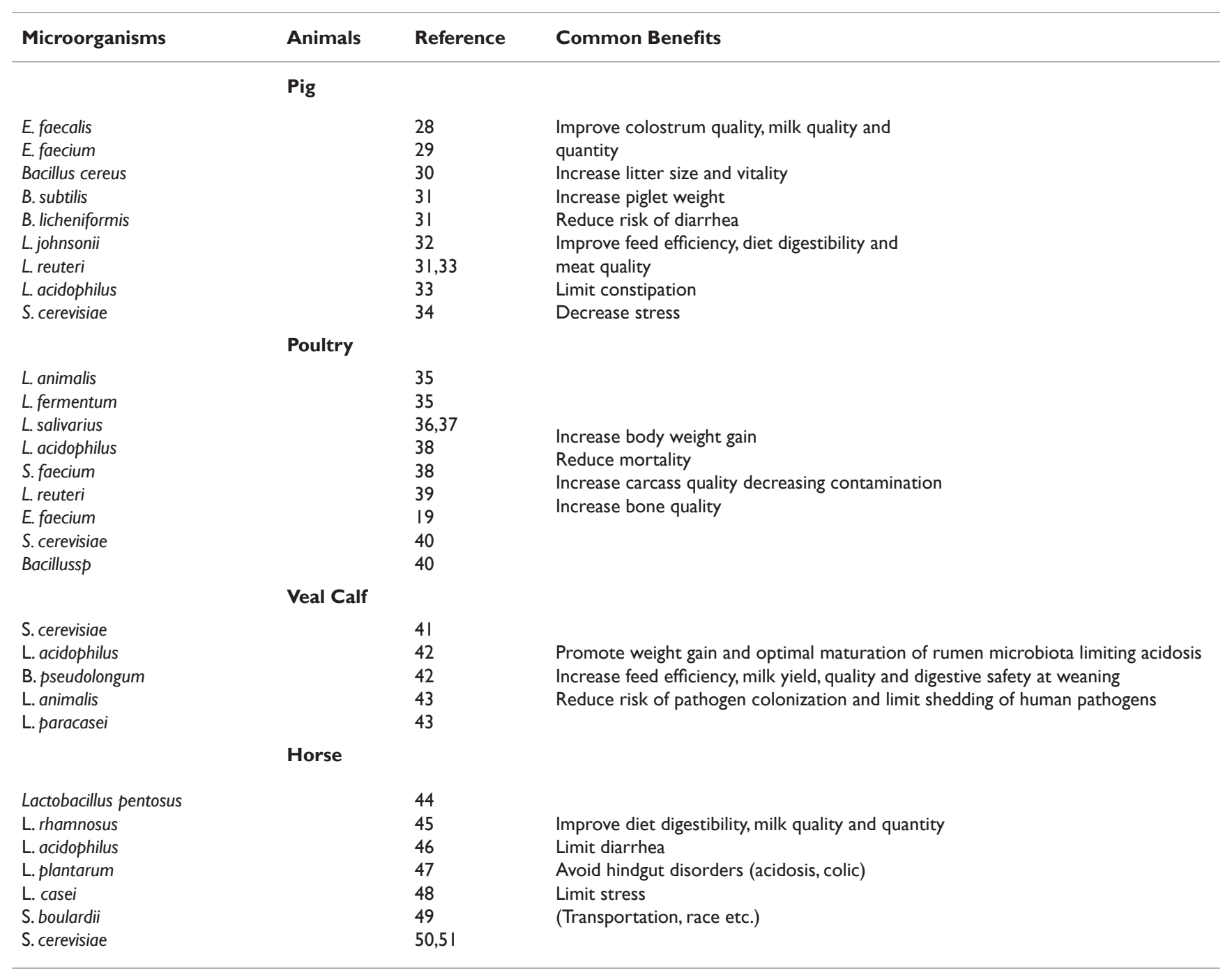

Table 2 Expected characteristics of ideal probiotics ${ }^{6,53-55}$

I.To have a confirmed favorable effect on the host demonstrating ability to exert at least one scientifically-supported health-promoting property.

2.To be non-pathogenic, non-toxic and free of significant adverse side effects on targeted species.

3.To have a precise taxonomic recognition.

4. To be a normal inhabitant and modify intestinal microbiota of the targeted species.

5. To be able to survive, colonize and being metabolically active in the targeted site, which implies:

I) Resistance to gastric juice and bile

2) Persistence in the gastrointestinal tract

3) Adhesion to gastrointestinal tract epithelium or mucus

4) Competition with the resident microbiota 
Table Continued..

6. To secrete molecules that are:

a) Freely diffusible, membrane permeable being intercepted by specific receptors at the cell surface.

b) Metabolic and pure signaling molecules which stimulate concurrently precise structural, metabolic and signaling activities.

c) Bacteria/bacteria and microbe/host cross talk (Quorum Sensing including toxin antitoxin systems controlling programmed apoptosis and cell death).

7. To be genetically stable.

8. To be amenable and stable during industrial processing, storage and delivery.

9. To be viable at high populations.

10. To be able to restore pre-antibiotic baseline flora.

II.To be able to deliver therapeutics.

I2. To be able to enhance animal performance decreasing carcass contamination and ammonia and urea excretion in animals.

Europe market is alternative for probiotic products, with consumer consciousness levels much greater than in North America; European probiotic demand is predictable to rise at a CAGR of about $6.7 \%$ from 2013 to 2018. In European market, Germany and the UK are the most demandable markets, with projected CAGR of over $6 \%$ each from 2013 to 2018. The North American probiotics markets and emerging countries such as Brazil also show increase potential for demand growth. Based on the application, the probiotics market is classified into food and beverages, dietary supplements and animal feed that are further divided into segments. Probiotic foods \& beverages are the dominant segments the global market and are expected to grow at a CAGR of $6.8 \%$ from 2013 to 2018. Probiotic demand for food \& beverage segment is estimated to reach USD 37.9 billion in 2018 . Following food and beverages, the market for dietary supplements and animal feed are also witnessing significant growth, growing at a CAGR of $6.8 \%$ from 2013 to 2018 . With respect to application segments, probiotics are widely used in dairy, non-dairy, cereals, baked products, fermented meat products, dry foods and others. Dairy products are the largest application market for probiotic foods. Probiotic demand for dairy products is estimated to reach USD 32.2billion in 2018, growing at a CAGR of 6.8\% from 2013 to 2018. Probiotics have also emerged as a critical part of the animal feed industry with a demand for estimated to cross USD 3billion by $2018 .{ }^{62}$

\section{Fundamental criteria for selection of ideal probiotics in animal industry}

Functional, safety and technological characteristics have to be taken into account in the selection process of probiotic microorganisms. There are many microorganisms to be considered as potential probiotics, but only a few numbers of microorganisms are able to satisfy the necessary criteria. The probiotic bacteria must fulfill the following functional aspects, such as to be normal inhabitant of the gut, and to be able to persist in the gastrointestinal tract, surviving the digestive stresses, immunomodulation and the competition against other micro-organisms; finally, to have antagonistic and antimutagenic properties. ${ }^{63-67}$ Moreover, probiotics must reach the site of their main activity in the digestive tract unharmed to be efficacious. In the main target species this is the small intestine for monogastric animals together with the crop for poultry and the rumen for ruminants. Since factors such as $\mathrm{pH}$, the transit time of the digest a and the concentration of active substances in the feed can influence the growth of probiotics ${ }^{66,67}$ their growth or germination in the digestive tract must be evaluated in feeding trials using diets which are relevant under practical conditions. This can be measured indirectly via performance parameters but, better, directly by counting the living probiotic microorganisms in the various intestinal segments.

Safety aspects include specifications such as origin (healthy respective animals' gastrointestinal tract), absence of any pathogenicity, nondigestive upsets, and transmissible antibiotic resistance gene. Probiotics, specifically Bifidobacteria and Lactobacilli, have a long history of safety with their use in fermented food and milk. Moreover, these bacteria especially Lactobacilli, are regularly encountered in nature: plants, animals, and in humans as a commensal microbiota. Lactobacilli, Bifidobacteria, Lactococci, and yeasts are classified in the category of organisms Generally Regarded as Safe (GRAS). On the other hand, a few cases of infections have been occurred in immunocompromised patients. ${ }^{68}$ Not all the probiotics used belong to this GRAS category such as Enterobacteria or Enterococci, but some strains of Enterobacteria or Enterococci are used as probiotics. ${ }^{69}$

Satisfactory technological criteria are also important for selection of probiotics in food and feed production along with safety and functional criteria. The food and feed manufacture, distribution, and storage reduced viability of probiotic bacteria. Lactic acid bacteria do not form spores as natural residents of the intestine. They are therefore, in ordinary dried form, unprotected against the chemical and physical stresses, for example during pelleting. It is hence necessary either to use them only for feed types which place little technical stress on the microorganisms (for example in milk replacers) or to protect them specifically against mechanical and heat impacts during feed manufacturing, transport and storage. Lactic acid bacteria may be give a protective coating using special technological procedures such as microencapsulation or microsphering, thus ensuring that these nonspore bacteria are able to reach the site of action intact and become active. The stability of the coating is determined by the quality of the process. ${ }^{6}$ On the other hand, for Bacillus spores is their natural stable form that allows them to survive in their original habitat, the soil, protected from extreme heat, cold and mechanical strain, without any loss in their vital potential. Various cell walls protect the nucleus from external stresses. This natural protection enables the Bacillus products to withstand massive strains during feed production and storage, such as high temperatures, pressure, shear forces or oxidation impacts. ${ }^{70-72}$ Therefore, Bacillus spores are suitable for all types of feeds. In addition, their vitality is not compromised by low $\mathrm{pH}$ values in the stomachs of monogastric animals. Spore quality and stability of the Bacillus products and their ability to germinate are influenced by the fermentation conditions during production. In case of yeast culture, yeasts are living fungi and are made dormant by drying. Since their 
external surface is more stable and less permeable in this state, yeasts survive many processes of feed production and storage undamaged. Then the presence of sufficient moisture and warmth in the digestive tract allows them to regain their metabolic activity. Also sensory characteristics such as unpleasant flavors or textures are important criteria to select probiotics. ${ }^{73}$

The proposed tentative ways for selection of probiotics as biocontrol agents in the animal industry are illustrated in Figure 2.
There are many in vitro assays established for the pre-selection of probiotic strains. ${ }^{74-76}$ In vitro assays could give idea to the selection of the competitiveness of the most promising strains which was evaluated in vivo for monitoring of their persistence in animal model. ${ }^{36}$ Furthermore, potential probiotics must exert its beneficial effects (e.g. enhanced nutrition, stimulation/suppression of immune responses and resistance to antibiotics) in the respective animal. Lastly, the probiotic must be viable under normal storage conditions as well as technologically suitable for industrial processes (e.g. lyophilized).

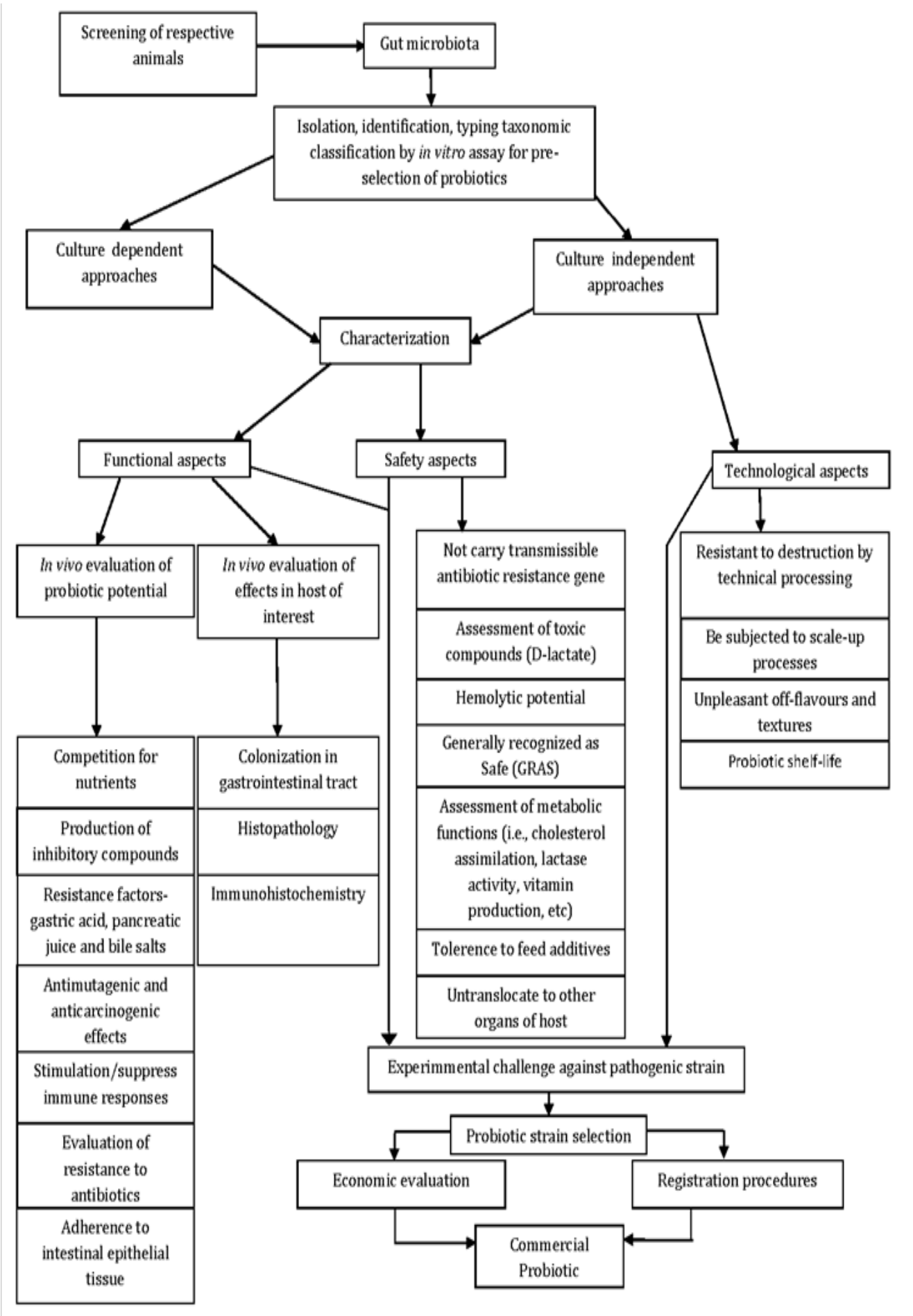

Figure 2 Diagram for selection of probiotics in the animal industry, modified from. . $^{36,7483}$ 


\section{Selected mechanisms of action of probiotics on mam- mals}

The mode of action of probiotics is not always well understood due to different probiotics strains may have various functions and survivability throughout the gut affecting the mammalian host in different ways. ${ }^{84}$

Effects of probiotics can be classified in:

A. Interaction between probiotic-microbe-gut epithelium: Adhesion to mucosal epithelial cells, stimulation of mucus secretion, prevention of adhesion of pathogens as probiotics blocking intestinal receptors, thereby excluding pathogens, enterotoxins and hampering proliferation of pathogens, competition with pathogens for important nutrients, secretion of antimicrobial and antitoxin substances that affects establishment and or replication of pathogens in the gastrointestinal tract. ${ }^{84,85}$

B. Interaction between probiotic-immune system: Immune-modulation by innate as well as systemic ways, enhancing and reinforcing gut integrity and gut barrier function, eventually decreasing secretory and inflammatory molecules against microbial infection. ${ }^{84}$ The general mechanisms by which probiotics may have an effect can be divided into various categories: adhesion activity to gut mucosal epithelium, antitoxic effect, modulation of immune system, production of antimicrobial substances and competitive exclusion between probiotics and pathogenic bacteria.

The advances on the knowledge of these mechanisms of action are detailed below.

Adhesion activity to gut mucosal epithelium: Adhesion property to the intestinal mucosa is the main selection criteria for new and existing probiotics strains for colonization, leading to the interaction between probiotics strains and host that is also related to the ability of strains to modulate the immune system. ${ }^{86-92}$ For many authors asses the adhesive ability of probiotics and good correlations have been established in various intestinal mucosa models system. ${ }^{93-99}$ Intestinal epithelial cells and mucus interact with lactic acid bacteria by showing different surface determinants from lactic acid bacteria. The principal component of mucous is mucin (complex glycoprotein mixture) that is secreted from intestinal epithelial cells. Mucin inhibits the adhesion of pathogenic bacteria. ${ }^{89,100}$ Anti-adhesiveness property by probiotics might be due to degradation of carbohydrate receptors by glycoprotein mixture, establishing a biofilm, production of receptor analogues and the induction of biosurfactants. Moreover, mucous gel is also composed of lipids, free proteins, immunoglobulins and salts. ${ }^{101}$

The specific interaction indicated a possible interaction association between the surface proteins of probiotic bacteria and the competitive exclusion of pathogens from the mucus. ${ }^{102-104}$ The most prominent mucus-targeting adhesin is a mucus-binding protein. Mucus-binding protein of Lactobacillus reuteri are either anchored to the membrane through a lipid moiety or embedded in the cell wall. ${ }^{105-109}$ Another kind of protein like mucous adhesion-promoting protein A from L. Reuteri and $L$. Fermentum mediate binding of these probiotics with mucus, specifically MUC2 and MUC3 mucins from L. Plantarum, inhibit the adherence of enteropathogenic $E$. Coli by enhanced mucous layers and glycocalyx overlying the intestinal epithelium as well as the occupation of microbial binding sites leading to protection against invasion by pathogens. ${ }^{102,110-112}$ Also adhesion of pathogenic Salmonella, Clostridium and E. Coli strains to pig intestinal mucus might be de- creased in the presence of MUC3 from probiotic Bifidobacterium lactis $\mathrm{Bb} 12$ and/or Lactobacillus rhamnosus LGG. ${ }^{113,114}$ Furthermore, our results on the adhesivity of $B$. Coagulans using the INT407 intestinal cell line ${ }^{81}$ and other authors previously ${ }^{115}$ have indicated its ability to strongly adhere to intestinal epithelium.

In contrast, other in vivo data suggested transient colonization, $B$. Coagulans being lost one week after administration. ${ }^{116}$ Therefore, daily administration of $B$. Coaugulans may be a prerequisite for efficacy. Moreover, a substantial population of growing vegetative cells in the gastrointestinal tract is not a prerequisite for the mode of action of Bacillus. ${ }^{117}$ The combination of probiotics and VSL3 showed to increase the synthesis of cell surface mucins and to modify mucin gene expression in a method dependent on the adhesion of bacterial cells to the intestinal epithelium. Moreover, some probiotics cause qualitative changes in intestinal mucins that help the prevention of pathogen binding. ${ }^{111,118}$ Many authors established that all probiotic strains and combinations tested showed capabilities to inhibit, displace and compete with pathogens, ${ }^{91,96,114}$ but it is important to take into account the high specificity of these processes to be tested thoroughly by mean of molecular approaches for acid tolerance, bile resistance and adhesion in mucus, cell lines, cells plus mucus in order to characterize the properties of the strains. Finally, human and animal clinical trials will be the definitive tool in order to select the best strain combinations functionality to prevent or treat infection by a specific pathogen.

Antitoxic effect: Bacterial toxins may be the most important bacterial virulence factors to produce diarrhea in mammals. Certain probiotics are able to protect the host against toxins inducing diarrhea by the inhibition of their expression in pathogens. For example, Bifidobacterium breve Yakult and Bifidobacterium pseudocatenulatum DSM20439 inhibit expression of Shiga toxin in E. Coli O157:H7 strains in vitro and in mice model. ${ }^{119}$ This indicated that the high concentration of acetic acid produced by strain Yakult is responsible for the inhibition of Shiga toxin expression. ${ }^{120}$ Probiotic Clostridium butyricum strain MIYAIRI protected gnotobiotic mice from enterohaemorrhagic $E$. Coli O157: H7 Shiga toxin-induced infection throughout production of butyric and lactic acid. Butyric acid, in particular, decreases also viability of enterohaemorrhagic $E$. Coli after neutralization (pH7). ${ }^{121}$ Furthermore, various probiotic Lactobacilli strains reduce Shiga toxin $2 \mathrm{~A}$ expression via production of sub-bactericidal concentrations of organic acids for enterohaemorrhagic E. Coli O157:H7. ${ }^{122}$ Both in the murine ileal loop model and in cell culture assays it was found that the probiotic yeast Saccharomyces cerevisiae (S. boulardii) shows effective protection against Clostridium difficile toxin A (TcdA). ${ }^{119}$ This protective interference occurred between $S$. Boulardii with the TcdA-induced inflammatory signal cascade activating Erk1/2 and JNK/ SAPK pathways. ${ }^{123,124}$ Additionally, $S$. boulardii is able to induce a specific anti-toxin A IgA immune response to destroy this toxin and secretes a protease that can hydrolyze TcdA and TcdB to inhibit their binding to their respective intestinal brush border receptors. ${ }^{125-127}$

Beside bacterial toxins, probiotics Lactobacillus rhamnosus $G G$ and L. Rhamnosus strain LC-705 are able to bind mycotoxins including aflatoxins. In rat model, L. Rhamnosus strain GG was able to modulate intestinal absorption and eventually increase fecal excretion of aflatoxin resulting in lowered toxicity expressed a sliver injury. ${ }^{128,129}$ In cell culture assay, L. Rhamnosus $G G$ decreased aflatoxin B1 uptake minimizing both membrane and DNA damage. ${ }^{130}$ Finally, designed probiotics carrying the receptor for the heat-labile enterotoxin of enterotoxigenic E. Coli or the receptor for cholera toxin showed good protection after enterotoxigenic E. Coli or Vibrio cholerae challenge in animal models. For some constructs formaldehyde-killed bacteria mediated also efficient protection as long as the frequency of applica- 
tion was increased. ${ }^{131}$

Modulation of immune system: Metabolites, cell wall components and DNA of probiotics can stimulate the immune system through interaction with epithelial and dendritic cells and with monocytes/ macrophages and lymphocytes either by innate or adaptive immune responses mechanism that might be local and limited to stimulation of gut immunity (stimulation of secretory IgA production for example) or systemic immunity. ${ }^{119,132-134}$ Peptidoglycan fragments or DNA (showed an anti-inflammatory reaction against DNA from pathogenic bacteria but mechanism of action is yet unknown) derived from probiotics $^{135}$ as well as immune modulatory effects might be even achieved with dead bacteria in mammalian body system. Mainly host cell receptors in gut epithelial and gut-associated immune cells recognize probiotics products by adhesion phenomena; generally the gut-associated immune system identifies intestinal microorganisms by pattern recognition receptors such as Toll-like receptors. Activation of the Toll-like receptors results trigger a signaling cascade lead to immune modulation (pro- and anti-inflammatory cytokine expression). ${ }^{136}$ Signaling cascades in immune cells or in epithelial cells that are stimulated by release of soluble factors, subsequently affect immune cells. Mainly gut $\mathrm{M}$ cells and dendritic cells play an important role to direct and indirect contact with probiotics to internalization of probiotics in the gut, and then present it to naïve $\mathrm{T}$ cells. This usually results to $\mathrm{T}$ cell activation and differentiation which eventually produced secretory $\operatorname{IgA}$ in gut environment through plasma cells and also increased expression of IL-10 in dendritic cells, indicating the important role of dendritic cells in immune modulation by probiotics, for example $L$. Rhamnosus. ${ }^{137,138}$

In healthy mammals, Lactobacillus rhamnosus GG (LGG) triggers the synthesis of the anti-inflammatory interleukin IL-10 which subsequently decrease the release of proinflammatory IFN- $\gamma$, IL-6 and TNF- $\alpha$ from CD4+ T cells pre-stimulated with intestinal bacteria. ${ }^{139}$ Teichoic acid, a component of the gram-positive cell wall of $L$. Plantarum is involved in the anti-inflammatory activity through the involvement of Toll-like receptors- 2 which highlighting the importance of Toll-like receptors for this probiotic actions. ${ }^{140}$ In our trials, the use of Pediococcus acidilactici in piglet significantly lowered intraepithelial $\mathrm{T}$ lymphocytes in the ileum $(\mathrm{P}=0.013)$ and numerically the number of $\mathrm{CD} 8$-intraepithelial $\mathrm{T}$ lymphocytes in the cecum. ${ }^{141}$ These observations are likely to be in relation with the presence of catarrhal enteritis in controls, in both ileum and cecum. It is conceivable that the intestinal mucosal barrier of $P$. Acidilactici treated piglets may be more efficient in contrasting the adhesion of bacterial pathogens than control piglets, at least in ileum. Our observation appears in ideal agreement with the results by Piva, Meola and Panciroli, ${ }^{142}$ who showed in an in vitro trial that Pediocin A did not display influences upon pig cecal microflora. It is conceivable that $P$. Acidilactici exerts in piglets its protective effects with regards to competition with potential pathogens, above all in the ileum (and only to a limited extent in cecum), possibly via the intervention of Toll-like receptors, which are essential for the control of intestinal host-microbial interactions and protection from the adhesion of microbial pathogens. ${ }^{141,143}$

Zonula occludens protein 1 and Zonula occludens protein 2 in the gut epithelium are two important proteins for preservation and maintenance of tight-junction function. Probiotics are able to protect the integrity of the mucosal gut barrier function against damages by the action of enteropathogenic Escherichia coli in a Toll-like receptor-independent way. Probiotics are able to restore disrupted epithelial barrier by changing protein kinase $\mathrm{C}$ signaling resulting in an amplification of expression and redistribution of zonula occludens protein
1 and zonula occludens protein 2 in cell culture and in mouse model. ${ }^{144}$ In broad spectrum, cellular signal transduction modulated by a number of probiotics that are capable to alter population of cytokine production. They can either block degradation of the inhibitor I $\mathrm{I} B$ or by interfering with proteasome function, which is, in turn activated through a peroxisome proliferator. ${ }^{145,146}$ Intestinal epithelial cell survival and growth maintain by probiotic Lactobacillus rhamnosus $G G$, which secrete two soluble proteins (designated p40 and p75). These proteins lead to inhibit TNF- $\alpha$ mediated apoptosis by activation of the anti-apoptotic factor Akt and protein kinase B and by inactivating the pro-apoptotic p38 mitogen-activating protein kinase signaling pathway in epithelial cells. ${ }^{147,148}$ Lastly, probiotic strains could induce release of small proteins/peptides like defensins/cryptidins from Paneth cells that reinforce and stabilize gut barrier function. ${ }^{149,150}$

Antimicrobial substances: Probiotics may be able to act through the production of antimicrobial substances. ${ }^{119,151}$

Overall, lactic acid bacteria can be divided into two groups on the basis of production of the antimicrobial metabolites:

a. Low molecular mass compounds ( $\leq 1000 \mathrm{Da})$ such as organic acids (acetic acid, lactic acid), nitrogen oxide, hydrogen peroxide and antimicrobial peptides (lantibiotics, lanthionin, heat stable non-lantibiotics and cyclic antimicrobial peptides) and reuterin which have a broad spectrum of action, and

b. Antimicrobial proteins, termed bacteriocins $(\geq 1000 \mathrm{Da})$ such as lactacin B, plantaricin and nisin that have a relatively narrow specificity of action against closely related organisms and other gram-positive bacteria. ${ }^{152,153}$

Reuterin showed broad spectrum antimicrobial activities against gram-positive, gram-negative bacteria as well as against yeast, fungi, protozoa and viruses. ${ }^{154}$ Acetic acid and lactic acid secreted in the fermentative metabolism of carbohydrates by probiotics, have a strong bacteriocidal effect against pathogens. ${ }^{155}$ These organic acids are the main antimicrobial compounds that are responsible for the inhibitory activity of probiotics against pathogens. ${ }^{156-158}$ The organic acid enters the bacterial cell in a undissociated form which dissociates inside its cytoplasm, subsequently resulting in a reduction of the intracellular $\mathrm{pH}$ that inhibits the growth of gram-negative bacteria due to their sensitivity to acidic conditions or the death of the pathogen due to the intracellular accumulation of the ionized form of the organic acid. ${ }^{156,158,159}$ Most of the research aimed to the characterization of bacteriocins or bacteriocin-like compounds focused on lactic acid bacteria, mainly Lactobacillus, Pediococcus and Enterococcus because of the diversity of these genera species and their potential applications as natural preservatives in foods ${ }^{153}$ and because of their activity against food borne pathogens like Listeria, Clostridium, Salmonella, Shigella, Escherichia, Helicobacter, Campylobacter and Candida. ${ }^{85,160-163}$ For example, Abp 118 like bacteriocin derived from Lactobacillus salivarius strain UCC118 is able to protect from infection against Listeria monocytogenes in mice model. ${ }^{164}$ In a study conducted by our research group, has demonstrated the capability of $B$. Coagulans to produce lactic and acetic acids in anaerobic conditions (42.27 $\pm 2.18 \mathrm{mmol} 1-1$ and $46.50 \pm 4.88 \mathrm{mmoll}-1)$ respectively. Thus, our results suggest that $B$. Coagulans strains isolated directly from calf feces could be considered a new single species probiotic supplement which can aid the maintenance of gastrointestinal health. ${ }^{81}$

Narrow spectrum Bacteriocins and small antimicrobial proteins are derived from lactic acid bacteria. Specifically, lactacin B, plantaricin and nisin are produced from L. Acidophilus, L. Plantarum and 
Lactococcus lactis respectively which are acting only against closely related bacteria. ${ }^{165}$ The most of bacteriocins kill susceptible bacteria through the damages of cells by membrane permeabilization or inhibition of cell wall synthesis by interference with essential bacterial enzymes. ${ }^{166}$ For instance, nisin forms a complex with lipid II (cell wall precursor of bacteria), preventing cell wall biosynthesis mainly in spore-forming bacilli. Eventually, formation of a pore occurs in the bacterial membrane due to the formation of complex aggregates and incorporates peptides. ${ }^{167}$ Finally, stronger antimicrobial activity of deconjugated bile acids is produced by probiotic bacteria. Functionally, de-conjugated bile acids show a stronger activity in comparison to bile salts synthetized by host organism. It is yet unclear and will need more investigation to clarify mechanisms by how probiotics protect themselves from their own bactericidal metabolites or if they are resistant to de-conjugated bile acids in mammalian gut at all. ${ }^{119}$ More research should be carried out in future on genetics, biochemistry and mechanism of action of probiotics due to the potential interest on novel approaches of these antimicrobial proteins and other antimicrobial metabolites in the field of pharmacotherapeutics developments.

Competitive exclusion between probiotics and pathogenic bacteria: Various bacterial genera colonized and are developed in the mammalian gut, producing an almost permanent exclusion environment by one species of bacteria that more vigorously competes for receptor sites mainly in the membrane of goblet cells, enteroendocrine cells and enterocytes of the intestinal tract than another species. Competitive exclusion mechanism represents a status of physical barrier to the gut mucosa by creating a special integrity systems characterized by creation of a hostile microecology, elimination of available bacterial receptor sites, production and secretion of antimicrobial substances and selective metabolites, and competitive depletion of essential nutrients, preventing intestinal pathogens from becoming established. ${ }^{168-171}$ The mechanisms used by one species of bacteria to exclude or reduce the growth of another species are varied due to strains variability of probiotics.

The interaction between surface proteins and mucins due to specific adhesiveness properties may inhibit the colonization of pathogenic bacteria leading to antagonistic activity by some strains of probiotics against adhesion of gastrointestinal pathogens. ${ }^{85}$ Growth and multiplication of a broad range of pathogens, such as E. Coli, Salmonella, Helicobacter pylori, Listeria monocytogenes and Rotavirus can be inhibited by Lactobacilli and Bifidobacteria. ${ }^{172-178}$ Some authors proposed that competitive exclusion might be based on binding to the same glycoconjugate receptor sites in a competitive manner on the epithelial surface by probiotics and pathogenic bacteria. ${ }^{179-181}$ More commonly, probiotic strains can prevent the attachment of pathogenic bacteria by steric hindrance at enterocyte pathogen receptors. ${ }^{181,182}$ In human mucosal material in vitro, ${ }^{112,183}$ chicken ${ }^{184}$ and pig mucosal material in vivo ${ }^{21}$ demonstrated the effect of probiotic bacteria on the competitive exclusion of pathogens A strongly adhering strain, L. Rhamnosus is able of preventing the internalization of enterohemorrhagic $E$. Coli in a human intestinal cell line. ${ }^{112}$ More recently, glyceraldehyde-3-phosphate dehydrogenase has an adhesion property that is expressed on the cell surface of $L$. Plantarum LA 318. Glyceraldehyde-3-phosphate dehydrogenase of Lactobacilli is capable to bind with human colonic mucins and enables to adhesion with Lactobacillus to compete with pathogens for a given binding site. ${ }^{185}$

\section{Application of probiotics in livestock}

Probiotics for pigs: Environmental stresses, mainly management methods, diet, etc. can affect swine production causing discrepancy in the intestinal diversity leading to a risk factor for pathogen infections. ${ }^{186}$ Weaning and post-weaning periods are the most stressful conditions in commercial porcine production resulting in transient drop in feed intake, inhibition of growth performance, negative influence on the immune function and the intestinal microbiota equilibrium finally leading to increased susceptibility to gut disorders, infections and diarrhea in the pigs. ${ }^{187}$ The increased level of probiotics use started after the full ban on in-feed antibiotics and the drastic reduction in the levels of incorporation of copper and zinc by the European Union. ${ }^{188}$ The majority of the researches showed a health beneficial effect of probiotic applied in piglets; increasing the number of intestinal beneficial bacteria, reducing the load of pathogenic bacteria, increased high activities of IgM, IgA against pathogens than control, enhanced defensive tools towards pathogenic invasion and increased villi morphology and function. Yeasts (Saccharomyces boulardii) and bacteria (Lactobacillus spp., Enterococcus spp., Pediococcus spp., Bifidobacterium spp., Bacillus spp.) are the most common probiotics use for monogastric animals to targeting the hindgut (caecum, colon) which harbors an abundant and very diverse quantity of microbial population mainly composed of bacteria and archaea. ${ }^{1}$

In gestating sows, the administration of probiotics have been reported to increase performance effects on feed intake and average live weight ${ }^{189}$ with at the same time a greater size and vitality of the neonatal piglets. ${ }^{190-192}$ On the contrary, our study found that Saccharomyces cerevisiae spp. Boulardii supplementation to sows had no beneficial effects on gestating sow body weights and feed intakes but total piglets born and born alive were in a larger number than in control sows. ${ }^{193}$ Furthermore, performance benefits of piglets have also been reported after weaning, as for example with S. Boulardii. ${ }^{194}$ In this study, the yeast promoted a 'healthy' intestine by an early restoration of the intestinal mucosal thinning and would possibly improve the local resistance to infection. Significant longer villi and deeper crypts were found in the ileum of piglets receiving diets supplemented with the yeast Saccharomyces cerevisiae spp. Boulardii ${ }^{195}$ or Pediococcus acidilactici. ${ }^{141,196}$ The benefits for intestinal $\operatorname{IgA}$ secretion and reduction of translocation of enterotoxinogenic E. Coli also observed with $S$. Boulardii or P. Acidi lacticifed to piglets. ${ }^{197}$ Strain of Lactobacillus sobrius provided on modulation of IgA development, mutually with a reduced ileal prevalence of enterotoxigenic $E$. Coli has been established. ${ }^{198}$

Bacillus species are also used as probiotics in some clinical trials in pigs. Inclusion of Bacillus subtilis strain in the feed resulted in a reduction of scours in weaned pigs challenged against K88-positive enterotoxigenic E. Coli as well as the spores of Bacillus licheniformis and $B$. Subtilis reduces the morbidity and the mortality in weaned piglets, improves the performance parameters of the fattening pigs and improves carcass quality. ${ }^{199,200}$ Furthermore, a combination of Bacillus subtilis and B. Licheniformis supplementation decreased gestating sows body weights, decreased incidence of diarrhea and mortality in piglets and improved litter weight at weaning and growth rate of young piglets. ${ }^{31}$ Moreover, the use of a $B$. Cereus based probiotic showed not only lower prevalence of diarrhea, but also that pigs needed to eat less food to attain the same weight gain..$^{30}$ Amusingly, probiotic supplemented in pigs resulted in an improvement in meat color, marbling, tenderness, flavor and juiciness in Korean swine production. ${ }^{201}$ Moreover, more sensitive to gut colonization happened from birth to post-weaning piglets by pathogenic bacteria (E. Coli, Clostridium difficile, Clostridium perfringens, Salmonella, Listeria), parasites (Isospora, Cryptosporidium) or viruses (Coronavirus, 
Rotavirus),which are responsible for growth reduction and diarrhea. During this episode, many studies have confirmed the efficacy of probiotics as well as therefore recommended to use probiotics in this period. ${ }^{198,202-204}$

The adaptive immune system of pigs has been influenced by the ability of probiotics which demonstrated in several studies. Szabo et al. ${ }^{205}$ found that the administration of E. Faecium improved the course of infection in weaning piglets when challenged with Salmonella Typhimurium, increased the production of specific antibodies against Salmonella. ${ }^{205}$ The distribution of intestinal immune cells (granulocytes, mast cells, CD4+, CD8+, CD25+, IgA+ lymphocytes) and the mucosal expression of cytokines (IFN- $\gamma$, TNF- $\alpha$, TGF- $\beta$, IL-10) by in vitro and in vivo studies on probiotic effects have been reported, but the effects of probiotics on those immune/defensive cells remain less clear. ${ }^{141,206-210}$ Moreover, many probiotic preparations have been tested in several separate laboratories with diverse and sometimes contradictory results. One of the most common methods used for assessment of immune function is the evaluation of lymphocyte proliferation, the principal actor in intestinal local immunity, whose anatomic counterpart was the gut-associated lymphoid tissue. More intriguing was the response to L. Fermentum in weaned pigs that induced an increase in the pro-inflammatory cytokines IFN- $\gamma$ and TNF- $\alpha$ in the ileum, and an increase in the percentage of CD4+ lymphocyte subset in blood. ${ }^{211}$

In comparison to poultry, competitive exclusion culture has not been studied thoroughly in pig. Known competitive exclusion culture from porcine reduced the mortality rate and reduced shedding of enterotoxigenic $E$. Coli in neonatal pigs ${ }^{21}$ as well as shed significantly lower pathogen numbers in neonatal pigs after challenge with Salmonella enteric serovar choleraesuis. ${ }^{20}$ Selected colicin-producing E. Coli targeting E. Coli $\mathrm{K}-88$ isolated from environmental sources (cattle and swine feces and soil) demonstrated a significant valuable effect on performance, diarrhea in weaning piglets infected with $E$. Coli K88. ${ }^{83}$ On the other hand, Enterococcus faecium and E. faecalis are routinely using in many clinical trials although they have not been proposed for QPS status by EU. ${ }^{212}$ In healthy piglets and sows, E. Faecium NCIMB 10415 decreased the pathogenic bacteria load through an interdisciplinary research study. ${ }^{192,213}$

The clinical trials utilizing Lactobacillus strains are increasing due to their documented importance as frequent component of pig microbiota. L. Sobrius significantly decreased the levels of enterotoxigenic $E$. Coli in the piglets' ileum when administered directly after weaning. Moreover, L. Sobrius improved daily weight gain in probiotic fed animals. ${ }^{198}$ L. Rhamnosus $G G$ (LGG) fed in postweaning piglets was effective in ameliorating diarrhea induced by E. Coli K88 via modulation of intestinal microflora, enhancement of intestinal and systemic immune response. ${ }^{214}$

Bifidobacterium species are most widely useful as probiotics in humans, but combination with Lactobacillus are conducted particularly in pigs. Lactobacilli and Bifidobacteria administration reduced the incidence and severity of necrotizing enterocolitis and reduced colonization density of the potential pathogen Clostridum perfringens immediately after birth. ${ }^{215}$ Probiotic preparations including Bifidobacteriumlactis and Lactobacillus rhamnosus individually lowered adherence of Salmonella, E. Coli and Clostridum spp. to the intestinal mucosa in swine. Together the two organisms were more effective and reduced each other's adherence. ${ }^{113}$

Microorganisms reside in the gut able to influence the phenotypic characteristics of enteric neurons of enteric nervous system. Kamm et al. ${ }^{216}$ showed that dietary probiotics (Saccharomyces cerevisiae sp. boulardii) affect the chemical coding of swine myenteric neurons and Bar et al., ${ }^{217}$ demonstrated that Escherichia coli Nissle 1917 affects the contractile activity of human isolated smooth muscle strips. Di Giancamillo el al. ${ }^{218}$ provided a quantitative evaluation of neuronal populations in the submucosal and myenteric plexuses of the pig ileum and cecum, and described specific changes in the neuronal and enteric glial cells in porcine treated with dietary P. Acidilactici, suggesting that changes in the intestinal microorganism community, like that linked to dietary probiotic administration, may conceptually support aspects related to enteric neuronal plasticity.

Probiotics for poultry: In modern broiler production practices, there are many factors that can enhanced stressors (feed changes or imbalances, transportation, processing at the hatchery and high stocking densities) during post hatching period, ${ }^{219}$ which ultimately affect the colonization of the gastrointestinal tract by bacterial pathogens due to weaken immune system, posing a threat to birds health and food safety. Salmonella spp. Campylobacter jejuni and Clostridium perfringens have been show to infect chickens and hens increasing the risk of contamination through the food chain resulting in a harmful condition both for poultry and human. ${ }^{220-222}$ So, probiotics act as a biological alternative in the preharvest control of Campylobacter, Salmonella, and Escherichia coli. ${ }^{53,223,224}$

Probiotics could be a possible strategy to control pathogen shedding and thus successfully demonstrates the impact of the intestinal microbiota on intestinal function and disease resistance. ${ }^{14,21,225}$ In poultry production, the application of probiotics is strictly associated with the concept of competitive exclusion, where 1-d-old chicks can be sheltered from succeeding Salmonella infections by accelerating the establishment of a complex, protective microflora. ${ }^{226,227}$ Many efficient commercial competitive exclusion cultures are also available on the market against Campylobacter ${ }^{14}$ and Clostridium perfringens. ${ }^{228}$ Zhang et al. ${ }^{229}$ indicated that cultures derived from free-range chickens on family poultry farms provided better competitive exclusion cultures in comparison to commercial farm chickens. ${ }^{229}$

The capability of probiotic strains to protect the growth of pathogens is believed to be important in preventing disease. Commercially lactic acid bacteria cultures have been widely used for their ability to reduce Salmonella infection in poultry and turkey production in many countries. ${ }^{230,231}$ In an all-inclusive research of 296 strains of lactic acid bacteria from the gut of 50 chicks, 77 of the strains were found to protect growth of enteropathogenic $S$. Enteritidis and E. Coli. ${ }^{36}$ Furthermore, the probiotic cultures modulated the microbial composition and the enzymatic activities of the cecal microbiota, resultant significant probiotic effect. ${ }^{186}$

Along with the control of food-borne pathogens in the poultry gut, selected probiotic cultures, mainly Lactobacillus spp., may also potentially increase production performance parameters; among poultry farmers, objectives (such as increasing growth rate, improving feed conversion and meat quality) are undoubtedly of primary importance. In a comprehensive in turkeys and chickens, commercial researches have established that proper administration of probiotics mixture increased performance, reduced costs of production as well as was effective in reducing abdominal fat deposition. ${ }^{232-236}$ Timmerman et al. $^{237}$ reported that the main factors affecting the efficacy of the probiotic preparations depend on way and timing of the administration. ${ }^{237}$ Application through the feed than application in the drinking water resulted in a higher increase of average daily 
gain. Furthermore, the supplementation of probiotics during early life of host is of great importance to the host because the probiotic bacteria can modulate intestinal epithelia genes expression to creating a favorable habitat for themselves.

Eggs production has been also investigated in relation to probiotic application. A combined mix culture of Lactobacillus acidophilus, L. Casei, Bifidobacterium thermophilus and Enterococcus faecium enhanced egg size and lowered feed cost in laying hens. ${ }^{238}$ Moreover, Bifidobacterium thermophilus and Enterococcus faecium improved egg production and quality. ${ }^{239}$ The use of Enterococci as probiotics is somewhat controversial in humans, but in chickens prolonged feeding with E. Faecium based probiotics increased egg laying intensity and feed conversion efficiency. ${ }^{240,241}$

In poultry, benefits of yeast probiotic supplementation are established in broilers' production performance and increased resistance of chickens to enteric pathogens infections (Salmonella, Campylobacter jejuni, E. coli or C. perfringens). ${ }^{230,242-244}$ Furthermore, supplementation with yeast treatment significantly decreased the frequency of Salmonella colonization to lower than the pre-stress (before transport) levels, whereas non-supplemented birds had higher levels of Salmonella colonization. ${ }^{245}$ Probiotics can increase feed efficiency and productivity of laying hens ${ }^{239,246}$ and an improvement in egg quality (decreased yolk cholesterol level, improved shell thickness, egg weight) has also been reported. ${ }^{239,247}$ Invernizzi et al., ${ }^{248}$ reported that selenium containing dead yeast (Saccharomyces cerevisiae) probiotic increased egg weight, egg shell quality with higher selenium concentration in egg and breast muscle. On the other hand, Zhang et al. ${ }^{249}$ conducted an experiment with male broilers to investigate the effects of Saccharomyces cerevisiae cell components on the meat quality and they reported that meat tenderness could be improved by the whole yeast or Saccharomyces cerevisiae extract. ${ }^{249}$

Probiotics for veal calves and horses: The most significant beneficial effects of probiotics have been established when probiotics included in the animals diet during specifically stressful periods for the gut microbiota and the animal. Due to undeveloped rumen in young pre-ruminants, lactic acid bacteria probiotic (Lactobacillus spp., Bifidobacterium spp., Enterococcus spp., Propionibacterium spp.) or Bacillus spores generally target the small intestine due to stabilize the gut microbes and limit the risk of enteric pathogen colonization.

Several in vivo trials have shown positive results with regard to animal performance, improved weight gain and rumen development in young calves with various type of bacterial and yeast strains supplementation. ${ }^{250}$ Calves fed milk fermented with either mixed lactic acid bacteria, or L. Acidophilus or S. Cerevisiae NCDC49 obtained reduce incidence of diarrhea. ${ }^{41}$ Moreover, viable E. Coli strain Nissle 1917 administered to calf had a clear favorable effect on the prophylaxis and treatment of neonatal calf diarrhea. ${ }^{251}$ Our lab reported that an investigation was carried out into the recovery from calf feces of Bacillus coagulans spores added to the feed as probiotic. ${ }^{81}$ Throughout the trial the fecal spore counts were significantly higher in the treated group than in the controls. In addition, the recovered cells were found to maintain their functionality aspects of acid production, survival in artificial gastric juice and in the presence of bile, and attachment to human intestinal epithelial cells in vitro. The results further elucidate the fate of spore formers administered to calves, and this will help in the development of new species-specific nutritional strategies. Improved weight gain and rumen development, improvement of lactic acid bacteria/E. Coli ratio and fecal score in young calves have been reported with several products. ${ }^{43,250,252,253}$ On the other hand, from the first days after birth, live yeast administered to calf has been helped to favor microbial colonization and the setup of fermentative capacities in the rumen. ${ }^{254}$ In young calves, incorporating live yeasts into the grain reduced the number of days with diarrhea. ${ }^{252}$

In horse, probiotic effects to the digestive compartment mainly caecum-colon. Fiber digestibility increased in the horse colon and modulated the balance of hindgut bacterial communities through supplementation with live yeast, consequently decreased risk of lactic acidosis. ${ }^{255,256}$ Agazzi el al. ${ }^{51}$ also reported that the administration of $S$. Cerevisiae to mature horses fed high-fiber diet increased apparent nutrient digestion rate. ${ }^{51}$ The apparent digestion rates of dry matter and organic matter were significantly improved in treated horses as compared with control subjects, but the most relevant difference among experimental groups was evidenced by a positive effect of the of live yeast over the fibrous fractions such as neutral detergent fiber and acid detergent fiber.

\section{Conclusions}

Most probiotic strains marketed today were originally selected for their superiority in a variety of easily measurable phenotypes, and not necessarily for their unique ability to confer defined health benefits. Unfortunately, the currently available in vitro tests are not accurate enough to predict the potential use and functionality of probiotic strains in vivo. Better knowledge of the structure and activities of the gut microbiota, functional interactions between gut microbes and interrelationships between microbes and host cells represent a fundamental aspect of future lactic acid bacteria probiotic research. The combination of verified molecular in vitro assays and in vivo animal models, through the monitoring of identified biomarkers with functional and comparative genomics and proteomics based approaches, should enable selection of the most appropriate probiotic strain for a particular health benefit or improvement of strain processing and/or administration regimes that strengthen the established health effect. At least the implementation of both in vitro and in vivo techniques will increase the knowledge of such an attractive perspective as the co-immobilization of probiotics microorganism with prebiotics, antioxidants, peptides or immuneenhancing compounds.

\section{Acknowledgements}

The authors would like to thanks Dr. Mariella Ferroni and Dr. Jessica Michela Caputo from Dipartimento di Scienze Veterinarie per la Salute, la ProduzioneAnimale e la Sicurezza Alimentare (VESPA), Facoltà di Medicina Veterinaria, Università degli Studi di Milano-20133, Italy for their valuable advices and encouragements for writing this manuscript.

\section{Conflict of interest}

Author declares that there is no conflict of interest.

\section{References}

1. Chaucheyras-Durand F, Durand H. Probiotics in animal nutrition and health. Benef Microb. 2010;1(1):3-9.

2. Choct M. Managing gut health through nutrition. Br Poult Sci. 2009;50(1):9-15.

3. Williams BA, Verstegen MW, Tamminga S. Fermentation in the large intestine of single-stomached animals and its relationship to animal health. 
Nutr Res Rev. 2001;14(2):207-228.

4. Brurberg MB, Nes IF, Eijsink VG. Pheromone-induced production of antimicrobial peptides in Lactobacillus. Molecular microbiology. 1997;26(2):347-360.

5. Chow J. Probiotics and prebiotics: A brief overview. Journal of renal nutrition: the official Journal of the Council on Renal Nutrition of the National Kidney Foundation. 2002;12(2):76-86.

6. Mitropoulou G, Nedovic V, Goyal A, et al. Immobilization technologies in probiotic food production. J Nutr Metab. 2013;2013.

7. Gibson GR, Fuller R. Aspects of in vitro and in vivo research approaches directed toward identifying probiotics and prebiotics for human use. The Journal of Nutrition. 2000;130(2 Suppl):391S-395S

8. Fuller R. Probiotics in man and animals. $J$ Appl Bacteriol. 1989;66(5):365-378.

9. Salminen S, von Wright A, Morelli L, et al. Demonstration of safety of probiotics-a review. Int J Food Microbiol. 1998;44(1-2):93-106.

10. Salminen S, Ouwehand A, Benno Y, et al. Probiotics: how should they be defined? Trends Food Sci and Tech. 1999;10(3):107-110.

11. Young G. Symbiosis: The bacteria diet. Nat Rev Micro. 2008;6(3):174-175.

12. FAO/WHO. Guidelines for the evaluation of probiotics in food. London: Report of a Joint FAO/WHO Working Group on Drafting Guidelines for the Evaluation of Probiotics in Food. FAO. 2002.

13. Nisbet DJ. Use of competitive exclusion in food animals. J Am Vet Med Assoc. 1998;213(12):1744-1746.

14. Stern NJ, Cox NA, Bailey JS, et al. Comparison of mucosal competitive exclusion and competitive exclusion treatment to reduce Salmonella and Campylobacter spp. colonization in broiler chickens. Poult Sci. 80(2): 156-160.

15. Berge AC, Wierup M. Nutritional strategies to combat Salmonella in mono-gastric food animal production. Animal. 2012;6(4):557-564.

16. Owings WJ, Reynolds DL, Hasiak RJ, et al. Influence of dietary supplementation with Streptococcus faecium M-74 on broiler body weight, feed conversion, carcass characteristics, and intestinal microbial colonization. Poult Sci. 1990;69(8):1257-1264.

17. Jin LZ, Ho YW, Abdullah N, et al. Growth performance, intestinal microbial populations, and serum cholesterol of broilers fed diets containing Lactobacillus cultures. Poult Sci. 1998;77(9):1259-1265.

18. Line JE, Bailey JS, Cox NA, et al. Effect of yeast-supplemented feed on Salmonella and Campylobacter populations in broilers. Poult Sci 1998;77(3):405-410.

19. Netherwood T, Gilbert HJ, Parker DS, et al. Probiotics shown to change bacterial community structure in the avian gastrointestinal tract. Appl Environ Microbiol 1999;65(11):5134-5138.

20. Genovese KJ, Anderson RC, Harvey RB, et al. Competitive exclusion of Salmonella from the gut of neonatal and weaned pigs. J Food Prot. 2003;66(8):1353-1359.

21. Genovese KJ, Anderson RC, Harvey RB, et al. Competitive exclusion treatment reduces the mortality and fecal shedding associated with enterotoxigenic Escherichia coli infection in nursery-raised neonatal pigs. Can J Vet Res. 2000;64(4):204-207.

22. Shenderov BA. Metabiotics: novel idea or natural development of probiotic conception. Microb Ecol Health Dis. 2013:24.

23. Fuller R. The Chicken Gut Microflora and Probiotic Supplements. $J$ Poultry Sci. 2001;38(3):189-196.

24. Mackie R, Aminov R, White B, et al. Molecular ecology and diversity in gut microbial ecosystems. In: Cronjé P, editor. Ruminant Physiology:
Digestion, Metabolism, Growth and Reproduction. London: CAB International; 2000;61-77.

25. Mueller S, Saunier K, Hanisch C, et al. Differences in fecal microbiota in different European study populations in relation to age, gender, and country: a cross-sectional study. Appl Environ Microbiol. 2006;72(2):1027-1033.

26. Abt MC, Artis D. The intestinal microbiota in health and disease: the influence of microbial products on immune cell homeostasis. Curr Opin Gastroenterol. 2009;25(6):496-502.

27. Ley RE, Hamady M, Lozupone C, et al. Evolution of mammals and their gut microbes. Science. 2008;320(5883):1647-1651.

28. Ozawa K, Yabu-uchi K, Yamanaka K, et al. Effect of Streptococcus faecalis BIO-4R on intestinal flora of weanling piglets and calves. Appl Environ Microbiol. 1983;45(5):1513-1518.

29. Deprez P, Branden Jvd, Geest Jd, et al. Deinvloed van Streptococcus faecium Toediening op de Excretie van Escherichia coli en het Coorkomen van Slingerziekte Bij Gespeende Biggen. Vlaams Diergeneskde Tijdschr. 1989;58:113-117.

30. Zani JL, da Cruz FW, dos Santos AF, et al. Effect of probiotic CenBiot on the control of diarrhoea and feed efficiency in pigs. J Appl Microbiol. 1998;84(1):68-71.

31. Mordenti A, Martelli G. Sporogenic Probiotics in Pig Farming. Rivista di Suinicoltura. 1999;40(5):30-41.

32. duToit M, Franz C, Dicks L, et al. Characterization and Selection of Probiotic Lactobacilli for a Preliminary Minipig Feeding Trial and Their Effect on Serum Cholesterol Levels, Faeces $\mathrm{pH}$ and Faeces Moisture Content. Int J Food Microbiol. 1998;40(1-2):93-104.

33. Azevedo MS, Zhang W, Wen K, et al. Lactobacillus acidophilus and Lactobacillus reuteri modulate cytokine responses in gnotobiotic pigs infected with human rotavirus. Beneficial microbes. 2012;3(1):33-42.

34. Price KL, Totty HR, Lee HB, et al. Use of Saccharomyces cerevisiae fermentation product on growth performance and microbiota of weaned pigs during Salmonella infection. J Anim Sci. 2010;88(12):3896-3908.

35. Reid G. In vitro testing of Lactobacillus acidophilus NCFMTM as a possible probiotic for the urogenital tract. Int Dairy J. 2000;10(5-6):415-419.

36. Garriga M, Pascual M, Monfort JM, et al. Selection of lactobacilli for chicken probiotic adjuncts. J Appl Microbiol. 1998;84(1):125-132.

37. Pascual M, Hugas M, Badiola JI, et al. Lactobacillus salivarius CTC2197 prevents Salmonella enteritidis colonization in chickens. Appl Environ Microbiol. 1999;65(11):4981-4986.

38. Morishita TY, Aye PP, Harr BS, et al. Evaluation of an avian-specific probiotic to reduce the colonization and shedding of Campylobacter jejuni in broilers. Avian Dis. 1997;41(4):850-855.

39. Casas IA, Edens FW, Parkhurst CR, et al. Probiotic Administrations of Lactobacillus reuteri Moderate Avian Growth Depression in Turkeys. Biosci and Microfl. 1998;17(2):125-131.

40. Kumprecht I, Zobac P. Continuous Application of Probiotics Based on Saccharomyces cerevisiae var elipsoideus and Bacillus C.I.P. 5832 in the Nutrition of Chicken Broilers. Zivocisna Vyroba. 1996;41:311-316.

41. Agarwal N, Kamra DN, Chaudhary LC, et al. Microbial status and rumen enzyme profile of crossbred calves fed on different microbial feed additives. Lett Appl Microbiol. 2002;34(5):329-336.

42. Abe F, Ishibashi N, Shimamura S. Effect of administration of bifidobacteria and lactic acid bacteria to newborn calves and piglets. $J$ Dairy $S c i$. $1995 ; 78(12): 2838-2846$

43. Agazzi A, Tirloni E, Stella S, et al. Effects of species-specific probiotic 
addition to milk replacer on calf health and performance during the first month of life. Ann Ani Sci. 2014;14(1):101-115.

44. Weese JS, Rousseau J. Evaluation of Lactobacillus pentosus WE7 for prevention of diarrhea in neonatal foals. $J$ Am Vet Med Assoc. 2005;226(12):2031-2034

45. Weese JS, Anderson ME, Lowe A, et al. Preliminary investigation of the probiotic potential of Lactobacillus rhamnosus strain GG in horses: fecal recovery following oral administration and safety. Can Vet J. 2003;44(4):299-302.

46. Swyers KL, Burk AO, Hartsock TG, et al. Effects of direct-fed microbial supplementation on digestibility and fermentation end-products in horses fed low- and high-starch concentrates. J Anim Sci. 2008;86(10):2596-2608.

47. Gabriele A, Georges B, Andrew C, et al. Scientific Opinion on the safety and efficacy of Lactobacillus plantarum (DSM 3676 and DSM 3677) and Lactobacillus buchneri (DSM 13573) as a silage additive for pigs, poultry, bovines, sheep, goats, rabbits and horses. EFSA Journal 2012;10(7):2780-2795.

48. Gabriele A, Alex B, Vasileios B, et al. Scientific Opinion on the safety and efficacy of Lactobacillus salivarius (CNCM I-3238) and Lactobacillus casei (ATTC PTA-6135) as silage additives for all species. EFSA Journal. 2012;10(9):2884-2898.

49. Desrochers AM, Dolente BA, Roy MF, et al. Efficacy of Saccharomyces boulardii for treatment of horses with acute enterocolitis. J Am Vet Med Assoc. 2005;227(6):954-959.

50. Mackenthun E, Coenen M, Vervuert I. Effects of Saccharomyces cerevisiae supplementation on apparent total tract digestibility of nutrients and fermentation profile in healthy horses. J Anim Physiol Anim Nutr (Berl). 2013;97(Suppl 1):1115-1120.

51. Agazzi A, Ferroni M, Fanelli A, et al. Evaluation of the Effects of Live Yeast Supplementation on Apparent Digestibility of High-Fiber Diet in Mature Horses Using the Acid Insoluble Ash Marker Modified Method. J Equ Vet Sci. 2011;31(1):13-18.

52. Collins JK, Thornton G, Sullivan GO. Selection of Probiotic Strains for Human Applications. Int Dairy J. 1998;8(5-6):487-490.

53. Patterson JA, Burkholder KM . Application of prebiotics and probiotics in poultry production. Poult Sci. 2003;82(4):627-631.

54. Shenderov BA. Probiotic (symbiotic) bacterial languages. Anaerobe. 2011;17(6):490-495.

55. Baugher JL, Klaenhammer TR. Invited review: Application of omics tools to understanding probiotic functionality. J Dairy Sci 2011;94(10):4753-4765.

56. Hosono A. Functions of Fermented Milk: Challenges for the Health Sciences. In: Nagasawa Y, Hosono A, editors. Fermented Milk in the Orient. London: Elsevier Applied Science; 1992.

57. Shortt C. The probiotic century: historical and current perspectives. Trends in Food Sci and Tech. 1999;10(12):411-417.

58. Rettger L, Cheplin H. A Treatise on the Transformation of the Intestinal Flora, with Special Reference to the Implantation of Bacillus acidophlus. New Haven: Yale University Press; 1921.

59. Stavric S, Kornegay E. Microbial probiotics for pigs and poultry. In: Wallace R, Chesson A, editors. Biotechnology in Animal Feeds and Animal Feeding. Weinheim, Germany: Wiley-VCH Verlag GmbH; 1995.

60. Rolfe RD. The role of probiotic cultures in the control of gastrointestinal health. J Nutr. 2000;130(2S Suppl):396S-402S.

61. Reid G, Friendship R. Alternatives to antibiotic use: probiotics for the gut. Anim Biotechnol. 2002;13(1):97-112.

62. Pedretti S. Probiotic market: up or down? Nutra foods. 2013;12:18-19.

63. Alander M, Satokari R, Korpela R, et al. Persistence of colonization of human colonic mucosa by a probiotic strain, Lactobacillus rhamnosus GG, after oral consumption. Appl Environ Microbiol. 1999;65(1):351-354.

64. Mattila-Sandholm T, Mättö J, Saarela M. Lactic acid bacteria with health claims - interactions and interference with gastrointestinal flora. Int Dairy J. 1999;9(1):25-35.

65. Saarela M, Mogensen G, Fondén R, et al. Probiotic bacteria: safety, functional and technological properties. J Biotechnol. 2000;84(3):197-215.

66. Chateau N, Castellanos I, Deschamps AM. Distribution of pathogen inhibition in the Lactobacillus isolates of a commercial probiotic consortium. J Appl Bacteriol. 1993;74(1):36-40.

67. Nurmi E, Schneitz CE, Makela PH. Process for the production of a bacterial preparation. Canadian Patent. 1983.

68. Cannon JP, Lee TA, Bolanos JT, et al. Pathogenic relevance of Lactobacillus: a retrospective review of over 200 cases. Eur J Clin Microbiol Infect Dis. 2005;24(1):31-40.

69. Franz CM, Huch M, Abriouel H, et al. Enterococci as probiotics and their implications in food safety. Int J Food Microbiol.s 2011;151(2):125-140.

70. Mazza P. The use of Bacillus subtilis as an antidiarrhoeal microorganism. Boll Chim Farm. 1994;133(1):3-18.

71. Sneath PHA. Endospore-forming Gram-Positive Rods and Cocci. In: PHA Sneath, editor. Bergey's manual? Of Systemic Bacteriology. USA: Williams \& Wilkins; 1986;2:1104-1141.

72. Madigan MT, Martinko JM, Parker J. Biology of Microorganisms. 10th ed. USA: Prentice Hall; 2003. p. 755-784.

73. Svensson U. "Industrial perspectives" in Probiotics: A Critical Review. In: Tannock GW, editor. Wymondham, UK: Horizon Scientific Press; 1999:57-64.

74. Ehrmann MA, Kurzak P, Bauer J, et al. Characterization of lactobacilli towards their use as probiotic adjuncts in poultry. $J$ Appl Microbiol. 2002;92(5):966-975.

75. Morelli L. In vitro selection of probiotic lactobacilli: a critical appraisal. Curr Issues Intest Microbiol. 2000;1(2):59-67.

76. Koenen ME, van der Hulst R, Leering M, et al. Development and validation of a new in vitro assay for selection of probiotic bacteria that express immune-stimulating properties in chickens in vivo. FEMS Immunol Med Microbiol. 2004;40(2):119-127.

77. Klaenhammer TR, Kullen MJ. Selection and design of probiotics. Int $J$ Food Microbiol. 1999;50(1-2):45-57.

78. Lee YK, Salminen S. Hand book of probiotics and Prebiotics. 2nd ed. New York: Wiley; 2009. p. 1-596.

79. Christophe L. Molecular tools for investigating the gut microbiota. In: D Charalampopoulos, R Rastall, editors. Prebiotics and Probiotics Science and Technology. New York: Springer; 2009. p. 33-78,

80. Ripamonti B, Agazzi A, Bersani C, et al. Screening of species-specific lactic acid bacteria for veal calves multi-strain probiotic adjuncts. Anaerobe. 2011;17(3):97-105.

81. Ripamonti B, Agazzi A, Baldi A, et al. Administration of Bacillus coagulans in calves: recovery from faecal samples and evaluation of functional aspects of spores. Vet Res Commun. 2009;33(8):991-1001.

82. Ripamonti B, Tirloni E, Stella S, et al. Effects of a species-specific probiotic formulation on multiresistant Escherichia coli isolates from the gut of veal calves. Czech J Ani Sci. 2013;58(5):201-207. 
83. Setia A, Bhandari SK, House JD, et al. Development and in vitro evaluation of an Escherichia coli probiotic able to inhibit the growth of pathogenic Escherichia coli K88. J Anim Sci. 2005;87(6):2005-2012.

84. Collado MC, Isolauri E, Salminen S, et al. The impact of probiotic on gut health. Curr Drug Metab. 2009;10(1):68-78.

85. Servin AL. Antagonistic activities of lactobacilli and bifidobacteria against microbial pathogens. FEMS Microbiol Rev. 2004;28(4):405-440.

86. Juntunen M, Kirjavainen PV, Ouwehand AC, et al. Adherence of probiotic bacteria to human intestinal mucus in healthy infants and during rotavirus infection. Clin Diagn Lab Immunol. 2001;8(2):293-296.

87. Schiffrin EJ, Brassart D, Servin AL, et al. Immune modulation of blood leukocytes in humans by lactic acid bacteria: criteria for strain selection. Am J Clin Nutr. 1997;66(2):515S-520S.

88. Beachey EH. Bacterial adherence: adhesin-receptor interactions mediating the attachment of bacteria to mucosal surface. J Infect Dis. $1981 ; 143(3): 325-345$.

89. Collado MC, Gueimonde M, Hernandez M, et al. Adhesion of selected Bifidobacterium strains to human intestinal mucus and the role of adhesion in enteropathogen exclusion. J Food Prot. 2005;68(12):2672-2678.

90. Collado MC, Gueimonde M, Sanz Y, et al. Adhesion properties and competitive pathogen exclusion ability of bifidobacteria with acquired acid resistance. J Food Prot. 2006;69(7):1675-1679.

91. Collado MC, Meriluoto J, Salminen S. Development of new probiotics by strain combinations: is it possible to improve the adhesion to intestinal mucus? J Dairy Sci. 2007;90(6):2710-2716.

92. Bjorksten B. Environmental influences on the development of the immune system: consequences for disease outcome. Nestle Nutr Workshop Ser Pediatr Program. 2008;61:243-254.

93. Kirjavainen PV, Ouwehand AC, Isolauri E, et al. The ability of probiotic bacteria to bind to human intestinal mucus. FEMS microbiology letters. 1998;167(2):185-189.

94. Tuomola EM, Ouwehand AC, Salminen SJ. Chemical, physical and enzymatic pre-treatments of probiotic lactobacilli alter their adhesion to human intestinal mucus glycoproteins. Int J Food Microbiol. 2000;60(1):75-81.

95. Rinkinen M, Westermarck E, Salminen S, et al. Absence of host specificity for in vitro adhesion of probiotic lactic acid bacteria to intestinal mucus. Vet Microbiol. 2003;97(1-2):55-61.

96. Gueimonde M, Noriega L, Margolles A, et al. Ability of Bifidobacterium strains with acquired resistance to bile to adhere to human intestinal mucus. Int J Food Microbiol. 2005;101(3):341-346.

97. Vesterlund S, Paltta J, Karp M, et al. Measurement of bacterial adhesion-in vitro evaluation of different methods. J Microbiol Methods. 2005;60(2):225-233.

98. Ouwehand AC, Isolauri E, Kirjavainen PV, et al. The mucus binding of Bifidobacterium lactis Bb12 is enhanced in the presence of Lactobacillus GG and Lact. delbrueckii subsp. bulgaricus. Lett Appl Microbiol. 2000;30(1):10-13.

99. Ouwehand AC, Salminen S. In vitro Adhesion Assays for Probiotics and their in vivo Relevance: A Review. Micr Eco Healt and Dis. 2011;15(4).

100. Gonzalez-Rodriguez I, Sanchez B, Ruiz L, et al. Role of extracellular transaldolase from Bifidobacterium bifidum in mucin adhesion and aggregation. Appl Environ Microbiol. 2012;78(11):3992-3998.

101. Neutra M, Forstner J. Gastrointestinal mucus: synthesis, secretion and function. In: Johnson L, editor. Physiology of the Gastrointestinal Tract. 2nd ed. New york: Raven publishers; 1987.
102. Ouwehand AC, Salminen S, Tolkko S, et al. Resected human colonic tissue: new model for characterizing adhesion of lactic acid bacteria. Clin Diagn Lab Immunol. 2002;9(1):184-186.

103. Haller D, Colbus H, Ganzle MG, et al. Metabolic and functional properties of lactic acid bacteria in the gastro-intestinal ecosystem: a comparative in vitro study between bacteria of intestinal and fermented food origin. Syst appl microbiol. 2001;24(2):218-226.

104. Van Tassell ML, Miller MJ. Lactobacillus adhesion to mucus. Nutrients. 2011;3(5):613-636.

105. Goh YJ, Klaenhammer TR. Functional roles of aggregation-promoting-like factor in stress tolerance and adherence of Lactobacillus acidophilus NCFM. Appl Environ Microbiol. 2010;76(15):5005-5012.

106. Buck BL, Altermann E, Svingerud T, et al. Functional analysis of putative adhesion factors in Lactobacillus acidophilus NCFM. Appl Environ Microbiol. 2005;71(12):8344-8351.

107. Sanchez B, Gonzalez-Tejedo C, Ruas-Madiedo P, et al. Lactobacillus plantarum extracellular chitin-binding protein and its role in the interaction between chitin, Caco-2 cells, and mucin. Appl Environ Microbiol. 2011;77(3):1123-1126.

108. von Ossowski I, Reunanen J, Satokari R, et al. Mucosal adhesion properties of the probiotic Lactobacillus rhamnosus GG SpaCBA and SpaFED pilin subunits. Appl Environ Microbiol. 2010;76(7):2049-2057.

109. von Ossowski I, Satokari R, Reunanen J, et al. Functional characterization of a mucus-specific LPXTG surface adhesin from probiotic Lactobacillus rhamnosus GG. Appl Environ Microbiol. 2011;77(13):4465-4472.

110. Voltan S, Castagliuolo I, Elli M, et al. Aggregating phenotype in Lactobacillus crispatus determines intestinal colonization and TLR2 and TLR4 modulation in murine colonic mucosa. Clin Vaccine Immunol. 2007;14(9):1138-1148.

111. Kim YS, Ho SB. Intestinal goblet cells and mucins in health and disease: recent insights and progress. Current Gastroenterol Rep. 2010;12(5):319-330.

112. Hirano J, Yoshida T, Sugiyama T, et al. The effect of Lactobacillus rhamnosus on enterohemorrhagic Escherichia coli infection of human intestinal cells in vitro. Microbiol Immunol. 2003;47(6):405-409.

113. Collado MC, Grzeskowiak L, Salminen S. Probiotic strains and their combination inhibit in vitro adhesion of pathogens to pig intestinal mucosa. Curr microbial. 2007;55(3):260-265.

114. Collado MC, Meriluoto J, Salminen S. In vitro analysis of probiotic strain combinations to inhibit pathogen adhesion to human intestinal mucus. Food Res Int. 2007;40(5):629-636.

115. Rowan NJ, Deans K, Anderson JG, et al. Putative virulence factor expression by clinical and food isolates of Bacillus spp. after growth in reconstituted infant milk formulae. Appl Environ Microbiol. 2001;67(9):3873-3881.

116. Adami A, Cavazzoni V. Occurrence of selected bacterial groups in the faeces of piglets fed with Bacillus coagulans as probiotic. J Basic Microbiol. 1999;39(1): 3-9.

117. Leser TD, Knarreborg A, Worm J. Germination and outgrowth of $B a-$ cillus subtilis and Bacillus licheniformis spores in the gastrointestinal tract of pigs. J Appl Microbiol. 2008;104(4):1025-1033.

118. Caballero-Franco C, Keller K, De Simone C, et al. The VSL\#3 probiotic formula induces mucin gene expression and secretion in colonic epithelial cells. Am j physiol Gastrointest liver physiol. 2007;292(1):G315G322.

119. Oelschlaeger TA. Mechanisms of probiotic actions - A review. Int J Med Microbiol. 2010;300(1):57-62. 
120. Asahara T, Shimizu K, Nomoto K, et al. Probiotic bifidobacteria protect mice from lethal infection with Shiga toxin-producing Escherichia coli O157:H7. Infect Immune. 2004;72(4):2240-2247.

121. Takahashi M, Taguchi H, Yamaguchi H, et al. The effect of probiotic treatment with Clostridium butyricum on enterohemorrhagic Escherichia coli $\mathrm{O} 157: \mathrm{H} 7$ infection in mice. FEMS Immunol Med Microbiol. 2004;41(3):219-226.

122. Carey CM, Kostrzynska M, Ojha S, et al. The effect of probiotics and organic acids on Shiga-toxin 2 gene expression in enterohemorrhagic Escherichia coli O157:H7. J Microbiol Methods. 2008;73(2):125-132.

123. Chen X, Kokkotou EG, Mustafa N, et al. Saccharomyces boulardii inhibits ERK1/2 mitogen-activated protein kinase activation both in vitro and in vivo and protects against Clostridium difficile toxin A-induced enteritis. J Biol Chem. 2006;281(34):24449-24454.

124. Chen X, Fruehauf J, Goldsmith JD, et al. Saccharomyces boulardii inhibits EGF receptor signaling and intestinal tumor growth in Apc(min) mice. Gastroenterology. 2009;137(3):914-923.

125. Qamar A, Aboudola S, Warny M, et al. Saccharomyces boulardii stimulates intestinal immunoglobulin A immune response to Clostridium difficile toxin A in mice. Infect immun. 2001;69(4):2762-2765.

126. Castagliuolo I, LaMont JT, Nikulasson ST, et al. Saccharomyces boulardii protease inhibits Clostridium difficile toxin A effects in the rat ileum. Infect Immun. 1996;64(12):5225-5232.

127. Castagliuolo I, Riegler MF, Valenick L, et al. Saccharomyces boulardii protease inhibits the effects of Clostridium difficile toxins A and B in human colonic mucosa. Infection and immunity. 1999;67(1):302-307.

128. Gratz S, Taubel M, Juvonen RO, et al. Lactobacillus rhamnosus strain GG modulates intestinal absorption, fecal excretion, and toxicity of aflatoxin B(1) in rats. Appl Environ Microbiol. 2006;72(11):7398-7400.

129. Turner PC, Wu QK, Piekkola S, et al. Lactobacillus rhamnosus strain GG restores alkaline phosphatase activity in differentiating Caco-2 cells dosed with the potent mycotoxin deoxynivalenol. Food Cheml Toxicol. 2008;46(6):2118-2123.

130. Gratz S, Wu QK, El-Nezami H, et al. Lactobacillus rhamnosus strain GG reduces aflatoxin B1 transport, metabolism, and toxicity in Caco-2 Cells. Appl Environ Microbiol. 2007;73(12):3958-3964.

131. Paton AW, Morona R, Paton JC. Designer probiotics for prevention of enteric infections. Nature rev Microbiol. 2006;4(3):193-200.

132. Butel MJ. Probiotics, gut microbiota and health. Méd Mal Infect. 2014;44(1):1-8.

133. Bermudez-Brito M, Plaza-Diaz J, Munoz-Quezada S, et al. Probiotic mechanisms of action. Ann nutr metab. 2012;61(2):160-174.

134. Viljanen M, Savilahti E, Haahtela T, et al. Probiotics in the treatment of atopic eczema/dermatitis syndrome in infants: a double-blind placebocontrolled trial. Allergy. 2005;60(4):494-500.

135. Rachmilewitz D, Katakura K, Karmeli F, et al. Toll-like receptor 9 signaling mediates the anti-inflammatory effects of probiotics in murine experimental colitis. Gastroenterology. 2004;126(2):520-528.

136. Cario E. Bacterial interactions with cells of the intestinal mucosa: Toll-like receptors and NOD2. Gut. 2005;54(8):1182-1193.

137. Macpherson AJ, Uhr T. Induction of protective IgA by intestinal dendritic cells carrying commensal bacteria. Science. 2004;303(5664):1662-1665.

138. Braat H, van den Brande J, van Tol E, et al. Lactobacillus rhamnosus induces peripheral hyporesponsiveness in stimulated CD4+ $\mathrm{T}$ cells via modulation of dendritic cell function. Am J Clin Nutr. 2004;80(6):1618-1625.
139. Schultz M, Linde HJ, Lehn N, et al. Immuno modulatory consequences of oral administration of Lactobacillus rhamnosus strain GG in healthy volunteers. J Dairy Res. 2003;70(2):165-173.

140. Grangette C, Nutten S, Palumbo E, et al. Enhanced antiinflammatory capacity of a Lactobacillus plantarum mutant synthesizing modified teichoic acids. Proc Natl Acad Sci U S A. 2005;102(29):10321-10326.

141. Di Giancamillo A, Vitari F, Savoini G, et al. Effects of orally administered probiotic Pediococcus acidilactici on the small and large intestine of weaning piglets. A qualitative and quantitative micro-anatomical study. Histol Histopathol. 2008;23(6):651-664.

142. Piva A, Meola E, Panciroli A. Effect of Pediococcus pentosaceus FBB61, pediocin A producer strain, in caecal fermentations. $J$ Appl Bacteriol. 1995;78(6):616-620.

143. Rakoff-Nahoum S, Paglino J, Eslami-Varzaneh F, et al. Recognition of commensal microflora by toll-like receptors is required for intestinal homeostasis. Cell. 2004;118(2):229-241.

144. Zyrek AA, Cichon C, Helms S, et al. Molecular mechanisms underlying the probiotic effects of Escherichia coli Nissle 1917 involve ZO-2 and PKCzeta redistribution resulting in tight junction and epithelial barrier repair. Cell Microbiol. 2007;9(3):804-816.

145. Petrof EO, Kojima K, Ropeleski MJ, et al. Probiotics inhibit nuclear factor-kappaB and induce heat shock proteins in colonic epithelial cells through proteasome inhibition. Gastroenterology. 2004;127(5):1474-1487.

146. Kelly D, Campbell JI, King TP, et al. Commensal anaerobic gut bacteria attenuate inflammation by regulating nuclear-cytoplasmic shuttling of PPAR-gamma and RelA. Nat Immunol. 2004;5(1):104-112.

147. Yan F, Polk DB. Probiotic bacterium prevents cytokine-induced apoptosis in intestinal epithelial cells. J Biol Chem. 2002;277(52):50959-50965.

148. Yan F, Cao H, Cover TL, et al. Soluble proteins produced by probiotic bacteria regulate intestinal epithelial cell survival and growth. Gastroenterology. 2007;132(2):562-575.

149. Furrie E, Macfarlane S, Kennedy A, et al. Synbiotic therapy (Bifidobacterium longum/Synergy 1) initiates resolution of inflammation in patients with active ulcerative colitis: a randomised controlled pilot trial. Gut. 2005;54(2):242-249.

150. Wehkamp J, Harder J, Weichenthal M, et al. NOD2 (CARD15) mutations in Crohn's disease are associated with diminished mucosal alpha-defensin expression. Gut. 2004;53(11):1658-1664.

151. Wohlgemuth S, Loh G, Blaut M. Recent developments and perspectives in the investigation of probiotic effects. Inter $J$ Medi Microbiol. 2010;300(1):3-10.

152. Niku-Paavola ML, Laitila A, Mattila-Sandholm T, et al. New types of antimicrobial compounds produced by Lactobacillus plantarum. J Appl Microbiol. 1999;86(1):29-35.

153. Chen H, Hoover DG. Bacteriocins and their Food Applications. Com Rev in Food Sci and Food Saf. 2003;2(3):82-100.

154. Cleusix V, Lacroix C, Vollenweider S, et al. Glycerol induces reuterin production and decreases Escherichia coli population in an in vitro model of colonic fermentation with immobilized human feces. FEMS microbiol ecol. 2008;63(1):56-64.

155. Bruno FA, Shah NP. Inhibition of pathogenic and putrefactive microorganisms by Bifidobacterium spp. Milchwissenschaft. 2002;57(11-12):617-621.

156. Alakomi HL, Skytta E, Saarela M, et al. Lactic acid permeabilizes gram-negative bacteria by disrupting the outer membrane. Appl Environ Microbiol. 2000;66(5):2001-2005. 
157. De Keersmaecker SC, Verhoeven TL, Desair J, et al. Strong antimicrobial activity of Lactobacillus rhamnosus GG against Salmonella typhimurium is due to accumulation of lactic acid. FEMS Microbiol Lette. 2006;259(1):89-96.

158. Makras L, Triantafyllou V, Fayol-Messaoudi D, et al. Kinetic analysis of the antibacterial activity of probiotic lactobacilli towards Salmonella enterica serovar Typhimurium reveals a role for lactic acid and other inhibitory compounds. Res Microbiol. 2006;157(3):241-247.

159. Russell JB, Diez-Gonzalez F. The effects of fermentation acids on bacterial growth. Adv microb Physiol. 1998;39:205-234.

160. Toure R, Kheadr E, Lacroix C, et al. Production of antibacterial substances by bifidobacterial isolates from infant stool active against Listeria monocytogenes. J Appl Microbiol. 2003;95(5):1058-1069.

161. Gagnon M, Kheadr EE, Le Blay G, et al. In vitro inhibition of Escherichia coli $\mathrm{O} 157: \mathrm{H} 7$ by bifidobacterial strains of human origin. Int J Food Microbiol. 2004;92(1):69-78.

162. Collado MC, Gonzalez A, Gonzalez R, et al. Antimicrobial peptides are among the antagonistic metabolites produced by Bifidobacterium against Helicobacter pylori. Int J Antimicrob Agents. 2005;25(5):385-391.

163. Collado MC, Hernandez M, Sanz Y. Production of bacteriocin-like inhibitory compounds by human fecal Bifidobacterium strains. J Food Prot. 2005;68(5):1034-1040.

164. Corr SC, Li Y, Riedel CU, et al. Bacteriocin production as a mechanism for the antiinfective activity of Lactobacillus salivarius UCC118. Proc Natl Acad Sci U S A. 2007;104(18):7617-7621.

165. Nielsen DS, Cho GS, Hanak A, et al. The effect of bacteriocin-producing Lactobacillus plantarum strains on the intracellular $\mathrm{pH}$ of sessile and planktonic Listeria monocytogenes single cells. Int J Food Microbiol. 2010;141(Suppl 1):S53-S59.

166. Hassan M, Kjos M, Nes IF, et al. Natural antimicrobial peptides from bacteria: characteristics and potential applications to fight against antibiotic resistance. J Appl Microbiol. 2012;113(4):723-736.

167. Bierbaum G, Sahl HG. Lantibiotics: mode of action, biosynthesis bioengineering. Curr pharm biotechnol. 2009;10(1):2-18.

168. Rantala M, Nurmi E. Hazards involved in the use of furazolidone for the prevention of salmonellosis in broiler chickens. J Hyg (Lond). 1974;72(3):349-354.

169. Soerjadi AS, Rufner R, Snoeyenbos GH, et al. Adherence of salmonellae and native gut microflora to the gastrointestinal mucosa of chicks. Avian Dis. 1982;26(3):576-584.

170. Salminen S, Isolauri E, Salminen E. Clinical uses of probiotics for stabilizing the gut mucosal barrier: successful strains and future challenges. Antonie van Leeuwenhoek. 1996;70(2-4):347-358.

171. Rolfe R. Colonization Control of Human Bacterial Enteropathogens in Poultry. In: Blankenship L, editor. Population dynamics of the intestinal tract. San Diego: Academic Press; 1991:59-75p.

172. Chenoll E, Casinos B, Bataller E, et al. Novel probiotic Bifidobacterium bifidum CECT 7366 strain active against the pathogenic bacterium Helicobacter pylori. Appl Environ Microbiol. 2011;77(4):1335-1343.

173. Sgouras D, Maragkoudakis P, Petraki K, et al. In vitro and in vivo inhibition of Helicobacter pylori by Lactobacillus casei strain Shirota. Appl Environ Microbiol. 2004;70(1):518-526.

174. Chu H, Kang S, Ha S, et al. Lactobacillus acidophilus expressing recombinant K99 adhesive fimbriae has an inhibitory effect on adhesion of enterotoxigenic Escherichia coli. Microbiol Immunol. 2005;49(11):941-948.
175. Tsai CC, Lin PP, Hsieh YM. Three Lactobacillus strains from healthy infant stool inhibit enterotoxigenic Escherichia coli grown in vitro. Anaerobe. 2008;14(2):61-67.

176. Munoz JA, Chenoll E, Casinos B, et al. Novel probiotic Bifidobacterium longum subsp. infantis CECT 7210 strain active against rotavirus infections. Appl Environ Microbiol. 2011;77(24):8775-8783.

177. Nakamura S, Kuda T, An C, et al. Inhibitory effects of Leuconostoc mesenteroides 1RM3 isolated from narezushi, a fermented fish with rice, on Listeria monocytogenes infection to Caco-2 cells and A/J mice. Anaerobe. 2012;18(1):19-24.

178. Todoriki K, Mukai T, Sato S, et al. Inhibition of adhesion of food-borne pathogens to Caco-2 cells by Lactobacillus strains. J Appl Micro. 2001;91(1):154-159.

179. Mukai T, Kaneko S, Matsumoto M, et al. Binding of Bifidobacterium bifidum and Lactobacillus reuteri to the carbohydrate moieties of intestinal glycolipids recognized by peanut agglutinin. Int J Food Microbiol. 2004;90(3):357-362.

180. Sun J, Le GW, Shi YH, et al. Factors involved in binding of Lactobacillus plantarum Lp6 to rat small intestinal mucus. Lett Appl Microbiol. 2007;44(1):79-85.

181. Coconnier MH, Bernet MF, Chauviere G, et al. Adhering heat-killed human Lactobacillus acidophilus, strain LB, inhibits the process of pathogenicity of diarrhoeagenic bacteria in cultured human intestinal cells. $J$ Diarrhoeal Dis Res. 1993;11(4):235-242.

182. Roselli M, Finamore A, Britti MS, et al. The novel porcine Lactobacillus sobrius strain protects intestinal cells from enterotoxigenic Escherichia coli $\mathrm{K} 88$ infection and prevents membrane barrier damage. J Nutr. 2007;137(12):2709-2716.

183. Tuomola EM, Ouwehand AC, Salminen SJ. The effect of probiotic bacteria on the adhesion of pathogens to human intestinal mucus. FEMS Immunol Med Microbiol. 1999;26(2):137-142.

184. Hirn J, Nurmi E, Johansson T, et al. Long-term experience with competitive exclusion and salmonellas in Finland. Int $J$ Food Microbiol. 1992;15(3-4):281-285.

185. Kinoshita H, Wakahara N, Watanabe M, et al. Cell surface glyceraldehyde-3-phosphate dehydrogenase (GAPDH) of Lactobacillus plantarum LA 318 recognizes human A and B blood group antigens. Res Microbiol. 2008;159(9-10):685-691.

186. Gaggia F, Mattarelli P, Biavati B. Probiotics and prebiotics in animal feeding for safe food production. Int J Food Microbiol. 2010;141(Supp1 1):S15-S28.

187. Modesto M, D’Aimmo MR, Stefanini I, et al. A novel strategy to select Bifidobacterium strains and prebiotics as natural growth promoters in newly weaned pigs. Livestock Science. 2009;122(2-3):248-258.

188. Commission of the European Communities EC. Commission regulation (EC) No. 1334/2003 of 25 July 2003 amending the conditions for authorisation of a number of additives in feeding stuffs belonging to the group of trace elements. Official Journal of European Union L. 2003;187:11-15.

189. Bohmer BM, Kramer W, Roth-Maier DA. Dietary probiotic supplementation and resulting effects on performance, health status, and microbial characteristics of primiparous sows. J Anim Physiol Anim Nutr (Berl). 2006;90(7-8):309-315.

190. Hong HA, Duc le H, Cutting SM. The use of bacterial spore formers as probiotics. FEMS Microbiol Rev. 2005;29(4):813-835.

191. Taras D, Vahjen W, Macha M, et al. Response of performance charac- 
teristics and fecal consistency to long-lasting dietary supplementation with the probiotic strain Bacillus cereus var. toyoi to sows and piglets. Arch Anim Nutri. 2005;59(6):405-417.

192. Taras D, Vahjen W, Macha M, et al. Performance, diarrhea incidence, and occurrence of Escherichia coli virulence genes during long-term administration of a probiotic Enterococcus faecium strain to sows and piglets. J Anim Sci. 2006;84(3):608-617.

193. Di Giancamillo A, Bontempo V, Savoini G, et al. Effects of live yeast dietary supplementation to lactating sows and weaning piglets. Int J Prob and Preb. 2007;2:55-66.

194. Bontempo V, Di Giancamillo A, Savoini G, et al. Live yeast dietary supplementation acts upon intestinal morpho-functional aspects and growth in weanling piglets. Animal Feed Science and Technology. 2006;129(3-4):224-236.

195. Di Giancamillo A, Bontempo V, Savoini G, et al. Morpho-functional-gut related and growth performance-related evidences that Levucell TM positively acts in sows and piglets. IV Intern Symp Dig Physiol in Pigs. 2003. p. 262-264.

196. Domeneghini C, Di Giancamillo A, Savoini G, et al. Structural patterns of swine ileal mucosa following L-glutamine and nucleotide administration during the weaning period. An histochemical and histometrical study. Histol Histopathol. 2004;19(1):49-58.

197. Lessard M, Dupuis M, Gagnon N, et al. Administration of Pediococcus acidilactici or Saccharomyces cerevisiae boulardii modulates development of porcine mucosal immunity and reduces intestinal bacterial translocation after Escherichia coli challenge. J Anim Sci. 2009;87(3):922-934.

198. Konstantinov SR, Smidt H, Akkermans AD, et al. Feeding of Lactobacillus sobrius reduces Escherichia coli $\mathrm{F} 4$ levels in the gut and promotes growth of infected piglets. FEMS microbiol ecol. 2008;66(3):599-607.

199. Bhandari SK, Xu B, Nyachoti CM, et al. Evaluation of alternatives to antibiotics using an Escherichia coli K88+ model of piglet diarrhea: effects on gut microbial ecology. J Anim Sci. 2008;86(4):836-847.

200. Alexopoulos C, Georgoulakis IE, Tzivara A, et al. Field evaluation of the effect of a probiotic-containing Bacillus licheniformis and Bacillus subtilis spores on the health status, performance, and carcass quality of grower and finisher pigs. $J$ Vet Med A Physiol Pathol Clin Med. 2004;51(6):306-312.

201. Yang SJ, Hyon JS, Yang CB, et al. Studies on the Effects of Feed Additives Fed to Pigs - Effects of Feeding Probiotics on the Growth Performance and Carcass Quality in Pigs. Korean J Animal Sci. 1998;40:21-30.

202. Casey PG, Gardiner GE, Casey G, et al. A five-strain probiotic combination reduces pathogen shedding and alleviates disease signs in pigs challenged with Salmonella enterica Serovar Typhimurium. Appl Environ Microbiol. 2007;73(6):1858-1863.

203. Taras D, Vahjen W, Simon O. Probiotics in pigs-modulation of their intestinal distribution and of their impact on health and performance. Livestock Science. 2007;108(1-3):229-231.

204. Lallès J-P, Bosi P, Smidt H, et al. Weaning - A challenge to gut physiologists. Livestock Science. 2007;108(1-3):82-93.

205. Szabo I, Wieler LH, Tedin K, et al. Influence of a probiotic strain of Enterococcus faecium on Salmonella enterica serovar Typhimurium DT104 infection in a porcine animal infection model. Appl Environ Microbiol. 2009;75(9):2621-2628.

206. Bai AP, Ouyang Q, Zhang W, et al. Probiotics inhibit TNF-alpha-induced interleukin-8 secretion of HT29 cells. World J Gastroenterol. 2004;10(3):455-457.

207. Menard S, Laharie D, Asensio C, et al. Bifidobacterium breve and Strep- tococcus thermophilus secretion products enhance T helper $1 \mathrm{immu}$ ne response and intestinal barrier in mice. Exp Biol Med (Maywood). 2005;230(10):749-756.

208. Rastall RA, Gibson GR, Gill HS, et al. Modulation of the microbial ecology of the human colon by probiotics, prebiotics and synbiotics to enhance human health: an overview of enabling science and potential applications. FEMS Microbiol Ecol. 2005;52(2):145-152.

209. Duncker SC, Lorentz A, Schroeder B, et al. Effect of orally administered probiotic E. coli strain Nissle 1917 on intestinal mucosal immune cells of healthy young pigs. Vet Immunol Immunopathol. 2006;111(3-4):239-250.

210. Galdeano CM, Perdigon G. The probiotic bacterium Lactobacillus casei induces activation of the gut mucosal immune system through innate immunity. Clin Vaccine Immunol. 2006;13(2):219-226.

211. Wang A, Yu H, Gao X, et al. Influence of Lactobacillus fermentum I5007 on the intestinal and systemic immune responses of healthy and $E$. coli challenged piglets. Antonie van Leeuwenhoek. 2009;96(1):89-98.

212. EFSA Scientific Committee. Introduction of a Qualified Presumption of Safety (QPS) approach for assessment of selected microorganisms referred to EFSA - Opinion of the Scientific Committee. EFSA Journal. 2007;587:1-16.

213. Lodemann U, Hubener K, Jansen N, et al. Effects of Enterococcus faecium NCIMB 10415 as probiotic supplement on intestinal transport and barrier function of piglets. Arch Anim Nutr. 2006;60(1):35-48.

214. Zhang L, Xu YQ, Liu HY, et al. Evaluation of Lactobacillus rhamnosus GG using an Escherichia coli K88 model of piglet diarrhoea: Effects on diarrhoea incidence, faecal microflora and immune responses. Vet Microbiol. 2010;141(1-2):142-148.

215. Siggers RH, Siggers J, Boye M, et al. Early administration of probiotics alters bacterial colonization and limits diet-induced gut dysfunction and severity of necrotizing enterocolitis in preterm pigs. $J$ Nutr. 2008;138(8):1437-1444.

216. Kamm K, Hoppe S, Breves G, et al. Effects of the probiotic yeast Saccharomyces boulardii on the neurochemistry of myenteric neurones in pig jejunum. Neurogastroenterology \& Motility. 2004;16(1):53-60.

217. Bar F, Von Koschitzky H, Roblick U, et al. Cell-free supernatants of Escherichia coli Nissle 1917 modulate human colonic motility: evidence from an in vitro organ bath study. Neurogastroenterol Motil. 2009;21(5):559-566.

218. Di Giancamillo A, Vitari F, Bosi G, et al. The chemical code of porcine enteric neurons and the number of enteric glial cells are altered by dietary probiotics. Neurogastroenterol Motil. 2010;22(9):e271-278.

219. Pinchasov Y, Noy Y. Comparison of post-hatch holding time and subsequent early performance of broiler chicks and Turkey poults. British Poultry Science. 1993;34(1):111-120.

220. Humphrey T, O'Brien S, Madsen M. Campylobacters as zoonotic pathogens: a food production perspective. Int J Food Microbiol. 2007;117(3):237-257.

221. Van Immerseel F, De Buck J, Pasmans F, et al. Clostridium perfringens in poultry: an emerging threat for animal and public health. Avian $\mathrm{Pa}$ thol. 2004;33(6):537-549.

222. Humphrey T. Are happy chickens safer chickens? Poultry welfare and disease susceptibility. Br Poult Sci. 2006;47(4):379-391.

223. Siragusa G, Ricke S. Probiotics as pathogen control agents for organic meat production. In: Ricke S, editor. Organic Meat Production and Processing. New York: Wiley-Blackwell publisher; 2012. p. 331-349.

224. Holzapfel WH, Schillinger U. Introduction to pre- and probiotics. Food Research International. 2002;35(2-3):109-116. 
225. Nisbet DJ, Tellez GI, Lowry VK, et al. Effect of a commercial competitive exclusion culture (Preempt) on mortality and horizontal transmission of Salmonella gallinarum in broiler chickens. Avian Dis. 1998;42(4):651-656.

226. Nurmi E, Nuotio L, Schneitz C. The competitive exclusion concept: development and future. Int J Food Microbiol. 1992;15(3-4):237-240.

227. Schneitz C, Nuotio L, Mead G, et al. Competitive exclusion in the young bird: challenge models, administration and reciprocal protection. Int $J$ Food Microbiol. 1992;15(3-4):241-244.

228. Kaldhusdal M, Schneitz C, Hofshagen M, et al. Reduced incidence of Clostridium perfringens-associated lesions and improved performance in broiler chickens treated with normal intestinal bacteria from adult fowl. Avian Dis. 2001;45(1):149-156.

229. Zhang G, Ma L, Doyle MP. Potential competitive exclusion bacteria from poultry inhibitory to Campylobacter jejuni and Salmonella. J Food Prot. 2007;70(4):867-873.

230. Higgins SE, Erf GF, Higgins JP, et al. Effect of probiotic treatment in broiler chicks on intestinal macrophage numbers and phagocytosis of Salmonella enteritidis by abdominal exudate cells. Poult Sci. 2007;86(11):2315-2321.

231. Higgins JP, Higgins SE, Wolfenden AD, et al. Effect of lactic acid bacteria probiotic culture treatment timing on Salmonella Enteritidis in neonatal broilers. Poult Sci. 2010;89(2):243-247.

232. Torres-Rodriguez A, Donoghue AM, Donoghue DJ, et al. Performance and condemnation rate analysis of commercial turkey flocks treated with a Lactobacillus spp.-based probiotic. Poult Sci. 2007;86(3):444-446.

233. Kalavathy R, Abdullah N, Jalaludin S, et al. Effects of Lactobacillus cultures on growth performance, abdominal fat deposition, serum lipids and weight of organs of broiler chickens. Br Poult Sci. 2003;44(1):139-144.

234. Torres-Rodriguez A, Higgins SE, Vicente JLS, et al. Effect of Lactose as a Prebiotic on Turkey Body Weight Under Commercial Conditions. $J$ Appl Poultry Res. 2007;16(4):635-641.

235. Vicente J, Higgins S, Bielke L, et al. Effect of Probiotic Culture Candidates on Salmonella Prevalence in Commercial Turkey Houses. J Appl Poultry Res. 2007;16(3):471-476.

236. Vicente J, Wolfenden A, Torres-Rodriguez A, et al. Effect of a Lactobacillus Species-Based Probiotic and Dietary Lactose Prebiotic on Turkey Poult Performance With or Without Salmonella Enteritidis Challenge. J Appl Poultry Res. 2007;16(3):361-364.

237. Timmerman HM, Veldman A, van den Elsen E, et al. Mortality and growth performance of broilers given drinking water supplemented with chicken-specific probiotics. Poult Sci. 2006;85(8):1383-1388.

238. Davis GS, Anderson KE. The effects of feeding the direct-fed microbial, primalac, on growth parameters and egg production in single comb white leghorn hens. Poult Sci. 2002;81(6):755-759.

239. Kurtoglu V, Kurtoglu F, Seker E, et al. Effect of probiotic supplementation on laying hen diets on yield performance and serum and egg yolk cholesterol. Food Addit Contam. 2004;21(9):817-823.

240. Koudela K, Holoubek J, Tyller M, et al. Nutritional Effects on Performance and Nitrogen Excretion in Dominant D-102 Laying Hens. Zivocisna Vyroba. 1996;41(2):75-81.
241. Panda AK, Rama Rao SS, Raju MVLN, et al. Effect of probiotic (Lactobacillus sporogenes) feeding on egg production and quality, yolk cholesterol and humoral immune response of White Leghorn layer breeders. $J$ Sci of Food and Agri. 2008;88(1):43-47.

242. Higgins SE, Higgins JP, Wolfenden AD, et al. Evaluation of a Lactobacillus-based probiotic culture for the reduction of Salmonella enteritidis in neonatal broiler chicks. Poult Sci. 2008;87(1):27-31.

243. La Ragione RM, Woodward MJ. Competitive exclusion by Bacillus subtilis spores of Salmonella enterica serotype Enteritidis and Clostridium perfringens in young chickens. Vet Microbiol. 2003;94(3):245-256.

244. Banjeree P, Pradhan NR. Live yeasts a good alternative to AGP in broiler chickens. World Poultry. 2006;22(8):32-34.

245. Line JE, Bailey JS, Cox NA, et al. Yeast treatment to reduce Salmonella and Campylobacter populations associated with broiler chickens subjected to transport stress. Poult Sci. 1997;76(9):1227-1231.

246. Yoruk MA, Gul M, Hayirli A, et al. The effects of supplementation of humate and probiotic on egg production and quality parameters during the late laying period in hens. Poult Sci. 2004;83(1):84-88.

247. Li L, Xu CL, Ji C, et al. Effects of a dried Bacillus subtilis culture on egg quality. Poult Sci. 2006;85(2):364-368.

248. Invernizzi G, Agazzi A, Ferroni M, et al. Effects of inclusion of selenium-enriched yeast in the diet of laying hens on performance, eggshell quality, and selenium tissue deposition. Ita J Ani Sci. 2013;12(1).

249. Zhang AW, Lee BD, Lee SK, et al. Effects of yeast (Saccharomyces cerevisiae) cell components on growth performance, meat quality, and ileal mucosa development of broiler chicks. Poult Sci. 2005;84(7):1015-1021.

250. Adams MC, Luo J, Rayward D, et al. Selection of a novel direct-fed microbial to enhance weight gain in intensively reared calves. Ani Feed Sci and Tech. 2008;145(1-4):41-52.

251. von Buenau R, Jaekel L, Schubotz E, et al. Escherichia coli strain Nissle 1917: significant reduction of neonatal calf diarrhea. J Dairy Sci. 2005;88(1):317-323.

252. Galvao KN, Santos JE, Coscioni A, et al. Effect of feeding live yeast products to calves with failure of passive transfer on performance and patterns of antibiotic resistance in fecal Escherichia coli. Reprod Nutr Dev. 2005;45(4):427-440.

253. Abu-Tarboush HM, Al-Saiady MY, Keir El-Din AH. Evaluation of diet containing Lactobacilli on performance, Fecal Coliform, and Lactobacilli of young dairy calves. Ani Feed Sci and Tech. 1996;57(1-2):39-49.

254. Chaucheyras-Durand F, Fonty G. Influence of a Probiotic Yeast (Saccharomyces cerevisiae CNCM I-1077) on Microbial Colonization and Fermentations in the Rumen of Newborn Lambs. Micro Eco in Heal and Dis. 2002;14(1):30-36.

255. Jouany JP, Gobert J, Medina B, et al. Effect of live yeast culture supplementation on apparent digestibility and rate of passage in horses fed a high-fiber or high-starch diet. J Anim Sci. 2008;86(2):339-347.

256. Medina B, Girard ID, Jacotot E, et al. Effect of a preparation of Saccharomyces cerevisiae on microbial profiles and fermentation patterns in the large intestine of horses fed a high fiber or a high starch diet. J Anim Sci. 2002;80(10):2600-2609. 